\section{UCDNN}

LIBRARY
University of Connecticut OpenCommons@UConn

$6-1-2005$

\title{
A Dynamic Smile Analysis in Young Adults
}

Christopher M. Maulik

Follow this and additional works at: https://opencommons.uconn.edu/sodm_masters

\section{Recommended Citation}

Maulik, Christopher M., "A Dynamic Smile Analysis in Young Adults" (2005). SoDM Masters Theses. 87.

https://opencommons.uconn.edu/sodm_masters/87 


\title{
A Dynamic Smile Analysis in Young Adults
}

\author{
Christopher Maulik, DMD \\ B.S., Binghamton University, 1998 \\ D.M.D., University of Connecticut Health Center, 2002
}

\author{
A Thesis \\ Submitted in Partial Fulfillment of the \\ Requirements for the Degree of \\ Master of Dental Science \\ at the \\ University of Connecticut
}

2005 


\title{
Approval Page
}

Master of Dental Science Thesis

\section{A DYNAMIC SMILE ANALYSIS IN YOUNG ADULTS}

\author{
Presented by
}

Christopher M. Maulik, B.S., D.M.D.
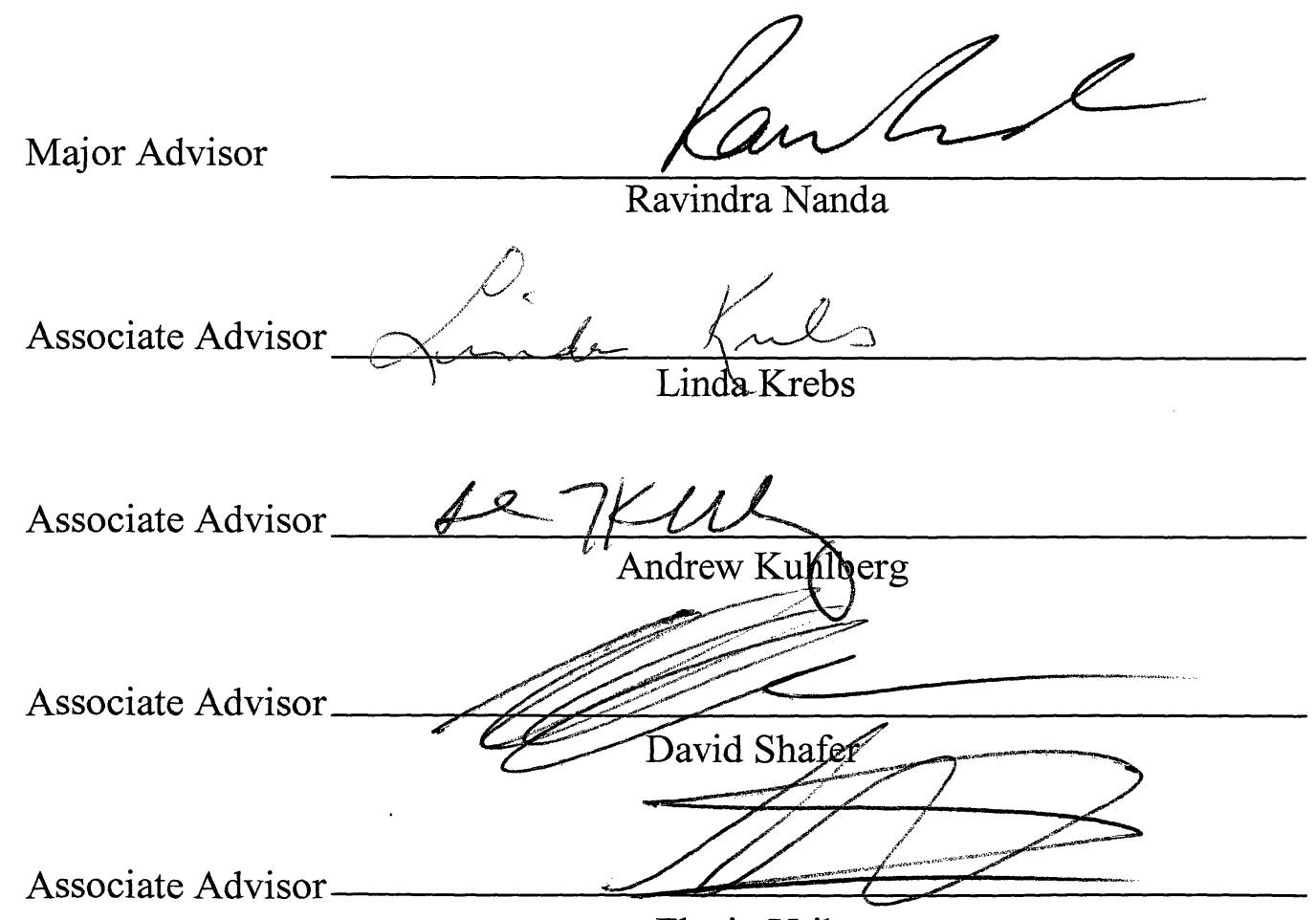

Flavio Uribe 


\section{$\underline{\text { Table of Contents }}$}

Section

Page

Introduction

1

Hypothesis

12

Specific Aims

14

Material and Methods

15

Results

24

Discussion

Conclusion

50

Figures

52

Literature Cited

74

Appendix

76 


\section{$\underline{\text { List of Tables }}$}

Table \#

1

2

3

4

5

6

7 Comparison of smile arc between orthodontically treated and non-trea.. 31

8 Comparison of buccal corridor between RME and non-expanded gro... 32

9 Univariate analysis of variance comparing buccal corridor 33

10 Comparison of most posterior tooth visible between RME and non-RME 35

13 Comparison of anterior smile height between orthodontically treated... 38

14 Comparison of posterior smile height between orthodontically treated... 39 


\section{Acknowledgements}

Firstly, I would like to thank Dr. Nanda for giving me the helping create this study. I enjoyed this project immensely and he allowed me to work independently yet was available to help whenever required. Also, I would like to thank Dr. Nanda for allowing me the opportunity to receive my orthodontic training at UCONN, I am proud to come from such a fantastic program.

Next I would like to thank Dr. Krebs for her many sessions of revisions. She was always very encouraging and pleasant to communicate with. I always looked forward to Dr. Kreb's revisions; they made sentences so much cleaner and concise.

I would like to thank Dr. Kuhlberg and Dr. Uribe for all their insightful suggestions and discussions we had about this project. I want to also thank Drs. Kuhlberg and Uribe for everything they have taught me about orthodontics. I hope one day I can know the breadth of the literature as Dr. Uribe or the depth of Dr. Kuhlberg's biomechanics knowledge. I would also like to thank Dr. Shafer for his outside input.

My wife Leila has been with me every step of the way offering technical and structural help to this project. She has been with me and positively influenced me for all my adult life. Thank you, Leila.

Lastly, I would like to thank my parents for encouraging me all my life and supporting me for 29 years. My Father has always stressed the importance of education and provided me with a good example. My Mother has always supported me $100 \%$ and the confidence I have in myself is to her credit. Without them I would not be where I am today. 


\section{Introduction}


The immeasurable value of an attractive smile is undeniable. A smile is considered to be the universal friendly greeting. It is often noted that a smile is a smile in any language. Its power is utilized by all people all over the world. An attractive smile in today's society is often considered an asset in an interview, in work settings, in social interactions, and even in the quest to attract a mate. Right alongside the designer pocketbook and upscale jewelry ads in a popular women's fashion magazine, an advertisement for a particular brand of veneers recently appeared, calling a beautiful smile "your most important accessory." For all the importance or even power we assign the smile, with our society's increasing emphasis on esthetics (most certainly including smile esthetics) and with the multi-million dollar industry that smile esthetics is becoming, one could quite naturally assume that the subject of smile esthetics and the impact of various treatment modalities on smile esthetics must be thoroughly exhausted. Yet, a perusal of the dental and orthodontic literature reveals that although there is a great deal of conjecture about "smile design" and treatment for smile esthetics, the sound scientific data is actually quite sparse. This study aimed to resolve some of these issues through quantifying various measurable parameters of a smile to determine smile norms, to compare these parameters in males and females, and to determine if a correlation exists between various orthodontic treatment modalities and the alteration of these norms.

\section{Objective of research}

There were five specific purposes to this study. First to use video to obtain adult averages for five different smile components: anterior and posterior smile heights, most posterior maxillary tooth visualized, smile arc in relation to lower lip, 
and buccal corridor size. The second purpose was to examine differences in smile arc parallelism to lower lip between orthodontically treated and non-treated individuals. Thirdly, buccal corridor size and most posterior tooth visible were compared between rapid maxillary expansion and non-expansion groups. Fourthly, differences between males and females were compared for the smile components examined. Finally, comparisons were made between the five components examined to determine the relationships between the measurements.

\section{$\underline{\text { Review of literature }}$}

Often the main reason people seek orthodontic care is to improve esthetics. It can be argued that the most visible display of teeth is during the smile. Sarver describes the importance of the smile, citing that "an attractive smile helps win elections, and beautiful smiles sell products" (Sarver 2001). Inconsistent with this, relatively little has been presented in the orthodontic and even entire dental literature on the esthetics of the smile. The mere fact that the $\mathrm{ABO}$ Certification does not even consider the smile in phase III case scoring is a testament to this.

Reasons for this lack of research could be due to several factors. Firstly, what is considered to be esthetic, in regards to smiles, is very subjective. Secondly, patient driven esthetics, particularly looking at the smile as opposed to the profile, is a relatively new concept in orthodontic treatment planning (Sarver and Ackerman 2000). Finally, a reason smiles have not been studied in the past could be due to the difficulty presented in capturing and measuring a reliable, repeatable smile.

Recent articles (Ackerman, Ackerman et al. 1998; Sarver 2001; Ackerman and Ackerman 2002; Sarver and Ackerman 2003; Sarver and Ackerman 2003) have been 
published that describe a new method of capturing and analyzing the smile through the use of videography and computer software. Ackerman and Sarver are two of the pioneers in the use of videography to analyze smiles. (Ackerman, Ackerman et al. 1998; Ackerman and Ackerman 2002; Sarver and Ackerman 2003; Sarver and Ackerman 2003) They used a digital video camera mounted on a microphone stand and placed it at a fixed distance from the patient. The lens was set to be "parallel to the true perpendicular of the face in natural head position" and the camera was adjusted to be level with the lower third of the patient's face. The patient was asked to repeat the phrase "Chelsea eats cheesecake by the Chesapeake", relax, and then to smile. Roughly 5 seconds of video was obtained for each patient. The video clip was downloaded to Apple Final Cut Pro where it was compressed into an Apple Quicktime movie file, approximately $4 \mathrm{MB}$. They found the smile portion to be typically $12-20$ frames in length, and the clip was searched for the single frame comprising the patient's best representation of a "natural unrestrained social smile." The selected smile frame was captured with Screen Snapz and saved as a JPEG file.

By using video, roughly 30 frames per second, it can be argued that one can attain a much more predictable, standardized smile, the widest commisure to commisure smile. By using computer software to extract the frame of the widest smile, one can reduce measurement error. The use of computer software allows for relative ease in analysis and measurements. Analyzing the smile and obtaining averages for it's different components can shed light upon a "standard of normalcy" (Tjan, Miller et al. 1984), thus serving as a guideline for the creation of an esthetic smile. 
To find a standard of normalcy in smile esthetics Tjan et al. (Tjan, Miller et al. 1984) looked at 454 full-face photographs of open smiles (those displaying teeth) to determine differences in smile type, number of teeth displayed, and maxillary incisal curve relative to lower lip. Their subjects were between the ages of 20 and 30 years. There was no mention of orthodontic treatment having been rendered to the subjects. They found $48(10.5 \%)$ of the subjects were classified as having high smile (total length of maxillary anterior teeth and a contiguous band of gingiva shown), 313 (68.9\%) subjects had an average smile (75\% to $100 \%$ maxillary anterior teeth revealed), and 93 (20.4\%) had a low smile (displaying less than $75 \%$ of maxillary anterior teeth). In number of teeth displayed, Tjan et al. found $7 \%$ revealed just the six anterior teeth, $48.6 \%$ showed the six anteriors and $1^{\text {st }}$ premolars, $40.6 \%$ displayed six anteriors and $1^{\text {st }}$ and $2^{\text {nd }}$ premolars, and $3.7 \%$ demonstrated six anteriors, $1^{\text {st }}$ and $2^{\text {nd }}$ premolars, and $1^{\text {st }}$ molars. They also found 385 subjects (84.8\%) had a "parallelism of the upper incisal curve with the inner curvature of the lower lip", while $63(13.8 \%)$ showed a straight smile line, and $6(1.3 \%)$ had a "reverse smile line".

Dong et al. (Dong, Jin et al. 1999) more recently repeated some of the same measurements as Tjan et al. to again find averages for esthetic smiles. They examined smile photographs of 240 Korean university students with normal occlusion that had never received any orthodontic treatment. Several elements of the smile were examined, including the upper lip position, parallelism of the anterior incisal curve with the lower lip, and the number of teeth displayed. They used many of the same definitions used by Tjan et al. For example, they recorded their upper lip position as high, average, or low; they noted their parallelism of upper teeth to lower lip as 
parallel, straight, or reverse. For upper lip position, they found an average upper lip position in $56 \%$ of subjects, a high lip position in $29 \%$, and $15 \%$ of subjects had an upper lip position. Sixty percent of the subjects had a parallel smile (incisal edges of maxillary anterior teeth are parallel to the upper border of the lower lip), 34\% showed a straight smile, and 5\% displayed a reverse smile. In respect to the number of teeth displayed, they discovered that most (57\%) of their subjects displayed to the second premolar, and only 2 subjects showed only to the canines.

Another important benefit to standardized computer analysis of the smile is the ability to evaluate how orthodontists alter the smile. Ackerman (Ackerman, Ackerman et al. 1998) and Hulsey (Hulsey 1970) both found that orthodontic treatment flattened the smile arc, but these studies used static photographs.

Ackerman et al. looked at 30 static smile photographs of orthodontically treated and untreated individuals to determine if orthodontic treatment changed lip to teeth relationships, including the smile arc or the buccal corridor (Ackerman and Ackerman 2002). This study found the buccal corridor decreased slightly with treatment, but the difference was not statistically significant. They also found 6 of the $19(32 \%)$ orthodontically treated patients changed from a consonant (smile arc parallel with lower lip) to a flat smile arc as a result of treatment. Only 1 of the $20(5 \%)$ nontreated individuals changed from consonant to flat smile arc, thus suggesting orthodontic treatment may create a less esthetic smile, in regards to smile arc.

Hulsey (Hulsey 1970) examined the smile photographs of 40 subjects, 20 orthodontically treated and 20 non-treated subjects with "normal occlusion" to find if orthodontically treated smiles were as attractive as "normal occlusion" smiles. $\mathrm{He}$ 
found that orthodontically treated subjects scored significantly lower in attractiveness by his panel member evaluators. He also found that the most attractive smiles showed a "near perfect harmony between the arcs of curvature of the incisal edges of the upper incisors and the upper border of the lower lip". A final pertinent observation made in his study was that the most attractive smiles displayed the upper lip at the gingival margin of the upper central incisors.

Peck and Peck, over several studies (Peck, Peck et al. 1992; Peck and Peck 1995), have found that a gender difference exists in the gingival smile line (a dentolabial configuration characterized by the exposure of the maxillary anterior gingiva during the full smile). They state that at maximum smile, the upper lipline is positioned $1.5 \mathrm{~mm}$ more superiorly in females than in males. They continue by saying that the gingival smile line appears to be a female lineament and that low smile line seems to be a male lineament.

In addition to the evidence based analyses of smiles, there is also considerable anecdotal suggestion or opinion regarding smile esthetics and the impact of orthodontics on the smile. For one, McNamara (McNamara 2000) mentions, without citing any evidence based literature, that "the maxilla can be widened by means of RME, increasing transpalatal width and eliminating or reducing the dark spaces in the buccal corridors". As a result of this belief, he lectures around the country that expanding, even in those without crossbite, by way of RME creates a more esthetic smile. This viewpoint has gained popularity, but with little, if any, published evidentiary support or refuting data. 
Moore et al. (Moore, Southard et al. 2005) recently examined the influence of the buccal corridor on smile attractiveness when judged by lay persons. They digitally altered the photos of 10 smiling subjects to vary the size of the buccal corridor. They chose 5 different buccal corridor sizes, by trial and error, to produce a range of smile fullness: narrow ( $28 \%$ buccal corridor), medium-narrow ( $22 \%$ buccal corridor), medium ( $15 \%$ buccal corridor), medium-broad (10\% buccal corridor), and broad ( $2 \%$ buccal corridor). They found that a broader smile (minimal buccal corridor) was judged most attractive. They concluded that large buccal corridors should be included in the problem list during orthodontic diagnosis and treatment planning.

\section{$\underline{\text { Rationale }}$}

This study was done to first establish dynamic norms for the smile measurements initially introduced by Tjan et al, anterior smile height, smile arc, and most posterior maxillary tooth visible. In addition we aimed to introduce norms for two other smile measurements, the posterior smile height and the buccal corridor. The above averages were used to compare smiles by orthodontic treatment versus nontreatment and between rapid maxillary expanded versus non-expanded subjects.

Anecdotally, there are reports of a popular treatment strategy, straight-wire, causing a flattening of the smile arc. Straight wire mechanics depend highly on the bracket prescription and the straight wire is employed to achieve the desired orthodontic results. It has been stated that orthodontic treatment may flatten the smile arc (Sarver 2001). In order to test this hypothesis, we compared the smile arc in orthodontically treated versus non-treated subjects. 
There are many proponents of the use of rapid maxillary expansion in noncrossbite patients. They often cite the creation of a more esthetic smile as a result of this treatment strategy by decreasing the buccal corridor. However, to date, there are no scientific studies to endorse this belief. To determine if the expanded subjects have a smaller buccal corridor, we compared rapid maxillary expanded subjects to nonexpanded subjects.

In addition to establishing the above norms and answering the above questions, we sought to analyze and quantify the differences in the smile components between males and females. We also examined the relationships between the various smile components in order to potentially pose future questions about causes and effects in smile esthetics.

\section{$\underline{\text { Scientific Background }}$}

Our study design was similar to that used by Ackerman and Sarver(Sarver and Ackerman 2003; Sarver and Ackerman 2003). Some key differences were the camera and the software used. In this study, a newer video camera (Canon GL-2, Tokyo, Japan) was used to create higher resolution jpeg files. The software used also differed, a PC based rather than a Mac based, video editing software program was used, Scenanlyzer (Vienna, Austria) which likely produced little, if any, difference in regards to the smile frame captured. 


\section{Definitions}

Tjan et al. and Dong et al. (Tjan, Miller et al. 1984; Dong, Jin et al. 1999) both looked at photographs of smiles to determine the height of the upper lip, the number of maxillary teeth shown and the relation of the maxillary incisal edges to the lower lip. They both categorized the height of the upper lip into three values: "high smile" showing a contiguous band of gingiva above the maxillary anterior teeth, "average smile" - showing between $75 \%$ to $100 \%$ maxillary anterior teeth, and "low smile" showing less than $75 \%$ of maxillary anterior teeth. The parallelism of maxillary anterior incisal curve with the lower lip was separated into three groups. First, parallel, where the incisal edges of the maxillary anterior teeth are parallel to the upper border of the lower lip. Second, straight, meaning the incisal edges of the maxillary anterior teeth are in a straight line. Thirdly, reverse, when the incisal edges of the maxillary anterior teeth curved in reverse to the upper border of the lower lip. The definitions used in this study roughly approximate those put forth by Tjan and Dong (Tjan, Miller et al. 1984; Dong, Jin et al. 1999).

The smile arc is a term added to the orthodontic literature by Sarver (Sarver 2001; Sarver and Ackerman 2003). He defines it as "the relationship of the curvature of the incisal edges of the maxillary incisors, canines, premolars, and molars to the curvature of the lower lip in the posed social smile." The definition for smile arc in this present study is the same as that stated by Sarver.

Buccal Corridor has been defined several times in the orthodontic literature. One of the first definitions was that of Frush and Fisher (Frush 1966). They defined buccal corridors as the spaces between the facial surfaces of the posterior teeth and the 
corners of the lips when the patient is smiling. Hulsey (Hulsey 1970) defined it as the distance between the most lateral points on the canines divided by the distance between the innermost corners of the lips. Johnson (Johnson and Smith 1995) briefly mentions that visible dentition width divided by smile width (distance from the most medial points on the lips at the angels of the mouth) provides the best measure of the buccal corridor. Most recently Moore (Moore, Southard et al. 2005) defined the buccal corridor as the difference between visible maxillary dentition width and inner commisure width divided by inner commisure width. This current study used the definition as stated by Moore. 


\section{Hypotheses}

1. Greater than $50 \%$ of subjects will show "average" anterior smile height (showing between $75 \%$ to $100 \%$ maxillary central incisor).

2. Greater than $50 \%$ of subjects will show the "average" posterior smile height (showing between $75 \%$ to $100 \%$ maxillary $1^{\text {st }}$ premolar).

3. Most subjects will show up to $1^{\text {st }}$ or $2^{\text {nd }}$ maxillary premolar, fewer will show the $1^{\text {st }}$ molar and even fewer will just show only the six maxillary anterior teeth.

4. The smile arc will be parallel to the lower lip in most subjects.

5. The orthodontically treated group will show less parallelism between smile arc and the lower lip than the non-treated group. The majority of the orthodontically treated group will have a flat smile arc.

6. The expansion group will show more posterior teeth than the non-expanded group. For example, the expansion group will show, on average, back to the $1^{\text {st }}$ molar, whereas the non-expanded subjects will only show, on average, back to the $1^{\text {st }}$ premolar. 
7. The expansion group will have less buccal corridor space compared to the nonexpanded group.

8. Females will show higher anterior smile height.

9. No relationship will exist between the variables. 


\section{$\underline{\text { Specific Aims }}$}

\section{$\underline{\text { Aims/Objectives }}$}

1. Use video to obtain adult averages for anterior and posterior smile heights and to determine the most posterior maxillary tooth visualized, smile arc parallelism, and buccal corridor ratio

2. Examine the smile components between males and females

3. Determine if a difference exists in smile arc parallelism between orthodontically treated and untreated individuals

4. Determine if expansion subjects have a difference in the size of the buccal corridor compared to non-expansion group

5. Examine if any difference exists in last maxillary tooth visualized between expansion and non-expansion groups

6. Examine the relationships between the smile components analyzed. 
Materials and Methods 


\section{$\underline{\text { Subjects }}$}

It was determined that a total of 210 subjects were required for this study.

These 210 subjects were to be separated into 3 groups, 70 non-orthodontically treated, 70 orthodontically treated without RME (rapid maxillary expansion), and 70 orthodontically treated with RME. The number of subjects required was determined by a NIH standard power analysis(Cohen 1988), which states that 70 subjects per group are required to show a "medium" (effect size is $.5=$ averages are $.5 \mathrm{SD}$ apart) difference in data.

The total sample at completion of the study consisted of 230 subjects. Females comprised $57 \%$ of the total and males $43 \%$. The average age of the total sample was 21.6 years, with a standard deviation of 5.8 years. The age ranged 14 to 35 years.

The sample was divided into three groups: non-orthodontically treated $(\mathrm{n}=73)$, orthodontically treated with $\mathrm{RME}(\mathrm{n}=73)$, and orthodontically treated without $\mathrm{RME}$ $(\mathrm{n}=87)$. Description of the sample is illustrated in table 1.

Group

Total Sample

Non-Treated

Orthodontically Treated with RME

Orthodontically Treated

without RME
Number

of Subjects 230 73

70

87
Females

(\%)

57

51

70

52
Males

(\%)

43

49

30

48
Standard

Average

Age

(years)

21.6

25.6

17.4

21.7
Deviation Age of Age Range (years) (years)

$5.8 \quad 14-35$

$4.7 \quad 14-35$

$4.2 \quad 14-34$

$5.4 \quad 14-32$

Table 1. Statistical description of the sample. 
University of Connecticut Institutional Review Board approval was obtained for the entire subject selection process. The subjects were retention patients in the University of Connecticut Orthodontic Clinic, students, employees, and residents of the UCONN Schools of Dental Medicine and Medicine. Also, to gather the needed amount of rapid maxillary expansion subjects, retention patients from local orthodontic offices were included.

The rapid maxillary expansion subjects from local orthodontists' offices were obtained by the orthodontist first examining their retention patient pools to find those that were de-bonded of fixed appliances and had been treated using rapid maxillary expansion. A list of potential subjects was created and they were contacted by either the author or by the orthodontic staff of the participating doctor. Once subjects consented, they returned to the office during one of several one to four hour time blocks that were established for the subjects to be videoed.

The potential subjects were told "I am an orthodontic resident and I am studying the differences in smiles between orthodontically treated and non-treated, and between maxillary expanded and non-expanded subjects. This study is completely anonymous and requires a brief video recording of you smiling. The video will only capture chin to nose."

The subjects were taken at random. The vast majority of potential subjects were willing to participate. All subjects agreed to participate in the local orthodontic offices. One declined in the University of Connecticut Orthodontic Clinic. Approximately five from the students, employees, and residents of the UCONN 
Schools of Dental Medicine and Medicine pool declined, and of those that did decline, they often cited they were too busy to help.

The inclusion criteria consisted of

1. 14 years of age to 35 years

2. any race

3. either sex

Exclusion criteria were:

1. Gross asymmetries

2. Craniofacial syndromes

3. Active orthodontic treatment (brackets on teeth)

\section{Data Gathering}

A miniDV video camera (Canon GL-2, Tokyo, Japan) was placed on a tripod approximately 4 feet away from the standing subject. The subject was instructed to hold their head in a natural position by looking forward as if they were looking at their eyes in the mirror (Moorees CFA 1958). The camera lens was adjusted, as close as possible, to be parallel to the apparent occlusal plane. The camera was focused only on the mouth, from the nose to the chin so the person could not be identified. The subject was instructed to say, "Chester eats cheesecake by the Chesapeake" and then to smile. Recording began approximately 1 second before the subject began speaking and ended after the smile. 
The subjects' age and gender were recorded on the questionnaire (Appendix). The subjects recruited from the students, employees, and residents of the UCONN Schools of Dental Medicine and Medicine were asked if they had orthodontic treatment, and if yes, then if they had rapid maxillary expansion. Some of the subjects were confused about RME, so it was explained to them that it was a screw-like device that would have been placed in the roof of their mouth that was turned every day. They were also asked if they had any permanent teeth extracted for orthodontic treatment. For the subjects from University of Connecticut Orthodontic Clinic their chart jacket was examined to see if "Rapid Palatal Expansion" or "Extractions" (this information is recorded on the outside jacket of retention patients' folders) had been circled and the subjects were asked to verify the information. The subjects from the local orthodontic offices were all in the RME pool so they were only asked to verify this and if they had permanent teeth extracted for orthodontic treatment. All subjects were deidentified using a code number, names were not noted. The time and date were also recorded on the questionnaire to aid in identifying the file in the future.

The video clip was then downloaded into to a Dell Inspiron 8200 (Plano, Texas) using Scenanlyzer (Vienna, Austria), a video editing software program. The video clips had the exact time and date as the file name. They were then renamed according to the subject number and the time and date stamp remained in the name for easy identification. Within Scenanlyzer, each frame of the video could be visualized, one frame at a time. The frame with the widest, commisure to commisure, smile was captured. Typically, the widest smile was viewed within 10 to 20 frames directly after the last word, "ches-a-PEAKE". The smile frame was converted into a jpeg file by 
Scenanlyzer and then renamed within Microsoft Windows XP Professional (Redmond, Washington). The file was named exactly the same as the video clip file, subject number and time date stamp.

The jpeg image was then opened in Adobe Photoshop (San Jose, California). The image was maximized on the screen and magnified so the lips and teeth occupied most of the screen (15 inch Dell LCD at 1600 X 1200 resolution). The following data were observed and entered in a Microsoft Excel spreadsheet (Redmond, Washington):

1. The anterior height of the smile (figure 1), entered as one of the following:
a. high smile - a contiguous band of gingiva above the maxillary central incisor

b. average smile - showing between $75 \%$ to $100 \%$ maxillary central incisor c. low smile - showing less than $75 \%$ of maxillary central incisor

2. The posterior height of the smile (figure 1), entered as one of the following:
a. high smile - a contiguous band of gingiva above the maxillary $1^{\text {st }}$ premolar

b. average smile - showing between $75 \%$ to $100 \%$ maxillary $1^{\text {st }}$ premolar c. low smile - less than $75 \%$ of maxillary $1^{\text {st }}$ premolar visible

3. The parallelism of smile arc in relation to the lower lip line (figure 2)

a. parallel - the maxillary incisal edges and canine and premolar cusp tips, from mesial to distal, follow the curvature of the lower lip 
b. flat - the maxillary incisal edges and canine and premolar cusp tips display no curvature relative the lower lip line

c. reverse - the incisal edges and canine and premolar cusp tips have a reverse curve relative the lower lip line

4. The most posterior maxillary tooth visible (figure 4), entered as one of the following:
a. canine
b. $1^{\text {st }}$ premolar
c. $2^{\text {nd }}$ premolar
d. $1^{\text {st }}$ molar
e. $2^{\text {nd }}$ molar

If a discrepancy between the two sides existed than the most posterior tooth of the two sides was entered.

5. The buccal corridor percentage (figure 3). For this measurement, the ruler tool was selected in Adobe Photoshop (San Jose, California). The ruler tool was drawn from the transversely widest point of the most posterior tooth on one side to the same point on the contralateral side. This measurement was then entered into a calculator. The ruler tool was then drawn from the transversely narrowest point visible in the innercommisure or buccal mucosa to the same point on the opposite side. This measurement was then divided by the visible maxillary inter-dental width. The resulting number was a ratio of the maxillary teeth within the smile minus the buccal corridor. For example, 0.88 meant the maxillary dentition occupied $88 \%$ of the inner 
inter-commisure width; the buccal corridor would then occupy $22 \%(100 \%-88 \%)$ of the smile. This is the number that was recorded in the Excel spreadsheet.

The data received from the questionnaire was entered in Excel with the appropriate subject number. Age was entered in years; sex was entered as "M" for male or "F" for female. "Yes" answers were coded as " 2 " and "no" answers as " 1 ".

\section{Data Analysis}

For the first four smile components listed (most posterior tooth visible, the anterior and posterior smile heights, and the smile arc) the frequencies were reported and respective charts made within Microsoft Excel. The buccal corridor average and standard deviation were obtained using SPSS (Chicago, Illinois), this was then entered back into the spreadsheet to make the appropriate graphs.

Comparisons and charts were made in Excel. Smile arc was compared between the orthodontically treated group and the non-treated group. The most posterior visible tooth and buccal corridor were compared between rapid maxillary expanded and non-expanded groups. Comparisons according to gender for all 5 variables were made. Finally comparisons were made between the 5 variables. For example, posterior smile height was compared to smile arc to determine if a relationship existed between the data. 


\section{$\underline{\text { Statistical Analysis }}$}

To test the statistical significance of the difference in smile heights, smile arc, and most posterior tooth visible between males and females, the Pearson chi square test was used. The same test was employed to test the statistical significance of the difference in smile heights, smile arc, and most posterior tooth visible between the orthodontically treated group and the non-treated group. The Pearson chi square was also used to test the significance of the difference of the most posterior tooth visible between rapid maxillary expanded and non-expanded subjects; the same test was used for testing significance of relationships between the smile heights, smile arc and most posterior tooth visible. The independent sample T-test was used to test the statistical significance of the difference in buccal corridor between rapid maxillary expanded and non-expanded groups. The independent sample T-test was also used when comparing the buccal corridor to the other variables. ANOVA was used to co-vary out gender when comparing buccal corridor between rapid maxillary expanded and non-expanded subjects. Kappa statistic was employed to evaluate the agreement among the multiple raters of the smile arc measurement. 


\section{$\underline{\text { Results }}$}




\section{Data Analysis}

The data analysis was based on 5 smile parameters, the anterior and posterior smile heights, the smile arc, the most posterior maxillary visible tooth, and the buccal corridor. For these 5 parameters, frequencies are reported for the entire sample. Comparisons are then made between gender, orthodontic treatment, and RME for each of the parameters.

The frequencies for anterior and posterior smile heights, smile arc, and most posterior maxillary visible tooth are displayed in figures $5,6,7$, and 8 respectively. Of the total sample, $56.9 \%$ showed average anterior smile height, $21.7 \%$ subjects showed low anterior smile height, $21.3 \%$ showed high anterior smile height (continuous band of gingiva above maxillary incisor).

The results for the posterior smile height for the total sample were $42.6 \%$ displayed high posterior smile height , 34.8\% displayed average posterior height ( $100 \%$ to $75 \%$ of maxillary $1^{\text {st }}$ premolar), and $22.6 \%$ displayed low posterior height.

For the smile arc, flat and parallel were the most common findings $49.1 \%$, and $40.4 \%$ respectively; whereas $10.4 \%$ subjects displayed a reverse smile arc.

The results for the most posterior maxillary tooth visible were as follows, $1.7 \%$ showed canine only, $22.2 \%$ displayed the $1^{\text {st }}$ premolar, $50.9 \%$ showed the $2^{\text {nd }}$ premolar, and $24.8 \%$ exhibited $1^{\text {st }}$ molars upon smile.

The average buccal corridor for the entire sample was $11.0 \%$ (SD 3.9\%) and a range of $2 \%$ to $24 \%$. 


\section{Comparisons}

Table 2. Comparison of anterior smile height between males and females.

\section{Crosstab}

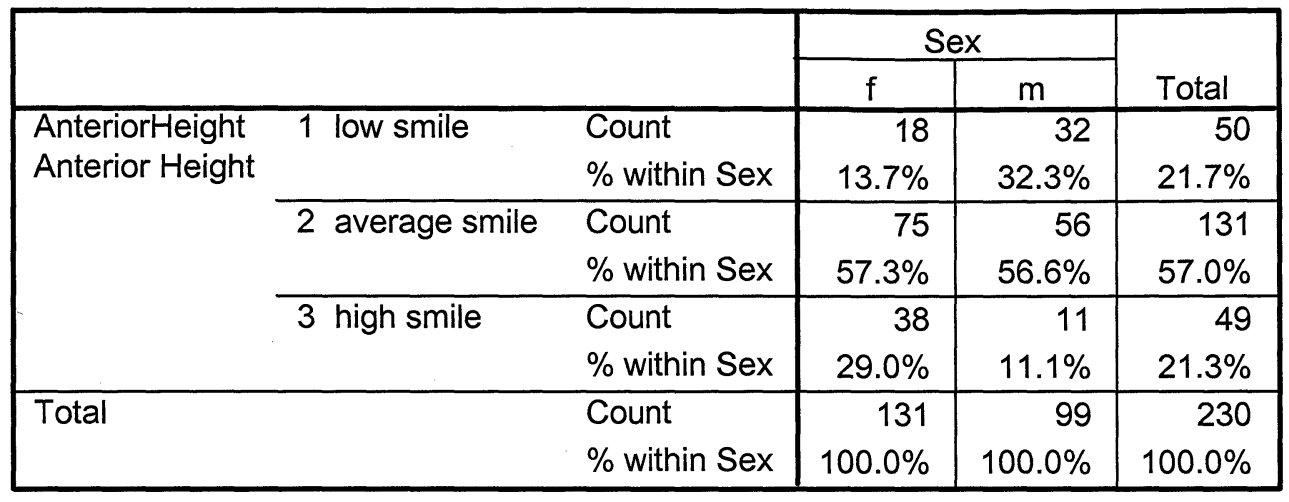

\section{Chi-Square Tests}

\begin{tabular}{|l|l|r|r|}
\hline & \multicolumn{1}{|c|}{ Value } & \multicolumn{1}{c|}{ df } & \multicolumn{1}{c|}{$\begin{array}{c}\text { Asymp. Sig. } \\
\text { (2-sided) }\end{array}$} \\
\hline Pearson Chi-Square & $17.439^{2}$ & 2 & .000 \\
Likelihood Ratio & 18.012 & 2 & .000 \\
N of Valid Cases & 230 & & \\
\hline
\end{tabular}

a. 0 cells $(.0 \%)$ have expected count less than 5 . The minimum expected count is 21.09 .

Females $(n=131)$ had a larger percentage $(29.0 \%)$ of subjects with a high anterior smile height compared to males $(11.1 \%)$. Males $(n=99)$ had a greater percentage $(32.3 \%)$ of subjects with low anterior smile compared to females $(13.7 \%)$. This difference is statistically significant $\left(\chi_{(1)}^{2}=17.439, \mathrm{p}=0.000\right)$. These results are displayed in table 2 and figure 9. 
Table 3. Comparison of posterior smile height between males and females.

Crosstab

\begin{tabular}{|lll|r|r|r|}
\hline & & & \multicolumn{2}{|c|}{ Sex } & \multirow{2}{*}{} \\
\cline { 4 - 6 } & & \multicolumn{1}{c|}{$\mathrm{f}$} & \multicolumn{1}{c|}{ Total } \\
\hline PosteriorHeight & 1 low smile & Count & 20 & 32 & 52 \\
Posterior Height & & \% within Sex & $15.3 \%$ & $32.3 \%$ & $22.6 \%$ \\
\cline { 2 - 6 } & 2 average smile & Count & 46 & 34 & 80 \\
& & \% within Sex & $35.1 \%$ & $34.3 \%$ & $34.8 \%$ \\
\cline { 2 - 6 } & \multirow{2}{*}{3 high smile } & Count & 65 & 33 & 98 \\
& & \% within Sex & $49.6 \%$ & $33.3 \%$ & $42.6 \%$ \\
\hline Total & & Count & 131 & 99 & 230 \\
& & \% within Sex & $100.0 \%$ & $100.0 \%$ & $100.0 \%$ \\
\hline
\end{tabular}

Chi-Square Tests

\begin{tabular}{|l|r|r|r|}
\hline & \multicolumn{1}{|c|}{ Value } & \multicolumn{1}{c|}{ df } & \multicolumn{1}{c|}{$\begin{array}{c}\text { Asymp. Sig. } \\
\text { (2-sided) }\end{array}$} \\
\hline Pearson Chi-Square & $10.775^{\mathrm{a}}$ & 2 & .005 \\
Likelihood Ratio & 10.778 & 2 & .005 \\
N of Valid Cases & 230 & & \\
\hline
\end{tabular}

a. 0 cells $(.0 \%)$ have expected count less than 5 . The minimum expected count is 22.38 .

Females $(\mathrm{n}=131)$ had a larger percentage $(49.6 \%)$ of subjects with a high posterior smile height compared to males $(33.3 \%)$. Males $(n=99)$ had a greater percentage (32.3\%) of subjects with low posterior smile compared to females $(15.3 \%)$. This difference is statistically significant $\left(\chi_{(1)}^{2}=10.775, p=0.005\right)$. These results are displayed in table 3 and figure 10. 
Table 4. Comparison of smile arc between males and females.

\section{Crosstab}

\begin{tabular}{|c|c|c|c|c|c|}
\hline & \multicolumn{2}{|c|}{ Sex } & \multirow[b]{2}{*}{ Total } \\
\hline & & & $f$ & $\mathrm{~m}$ & \\
\hline \multirow{6}{*}{$\begin{array}{l}\text { SmileArc } \\
\text { Smile Arc }\end{array}$} & 1 reverse & Count & 10 & 14 & 24 \\
\hline & & $\%$ within Sex & $7.6 \%$ & $14.1 \%$ & $10.4 \%$ \\
\hline & 2 flat & Count & 54 & 59 & 113 \\
\hline & & $\%$ within Sex & $41.2 \%$ & $59.6 \%$ & $49.1 \%$ \\
\hline & 3 parallel & Count & 67 & 26 & 93 \\
\hline & & $\%$ within Sex & $51.1 \%$ & $26.3 \%$ & $40.4 \%$ \\
\hline \multirow{2}{*}{\multicolumn{2}{|c|}{ Total }} & Count & 131 & 99 & 230 \\
\hline & & \% within Sex & $100.0 \%$ & $100.0 \%$ & $100.0 \%$ \\
\hline
\end{tabular}

\section{Chi-Square Tests}

\begin{tabular}{|l|l|r|r|}
\hline & \multicolumn{1}{|c|}{ Value } & \multicolumn{1}{c|}{ df } & \multicolumn{1}{c|}{$\begin{array}{c}\text { Asymp. Sig. } \\
\text { (2-sided) }\end{array}$} \\
\hline Pearson Chi-Square & $14.797^{\mathrm{a}}$ & 2 & .001 \\
Likelihood Ratio & 15.136 & 2 & .001 \\
N of Valid Cases & 230 & & \\
\hline
\end{tabular}

a. 0 cells $(.0 \%)$ have expected count less than 5 . The minimum expected count is 10.33 .

Females $(\mathrm{n}=131)$ had a higher frequency $(51.7 \%)$ of parallel smile arc compared to males $(26.3 \%)$. Males $(n=99)$ had a higher frequency $(14.1 \%)$ of reverse smile arc compared to females $(7.6 \%)$. This difference is statistically significant $\left(\chi_{(1)}^{2}=14.797\right.$, $\mathrm{p}=0.001)$. These results are displayed in table 4 and figure 11 . 
Table 5. Comparison of most posterior maxillary tooth visible between males and females.

MostPosteriorTooth Most Posterior Tooth * Sex Crosstabulation

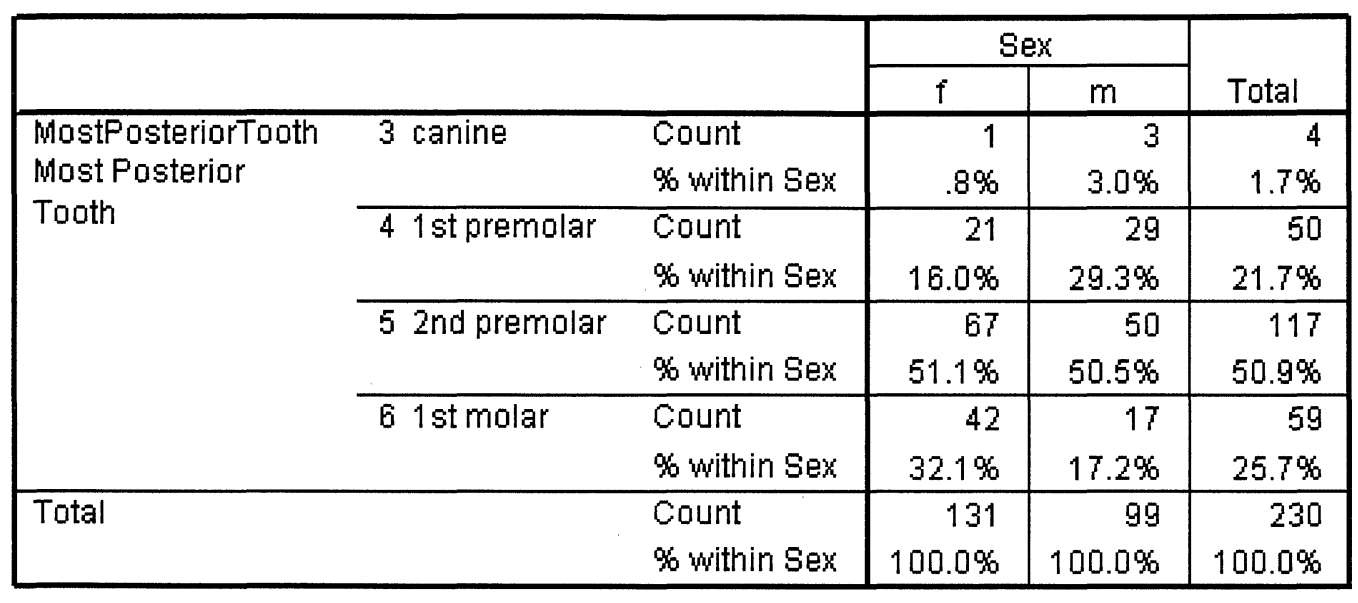

\section{Chi-Square Tests}

\begin{tabular}{|l|c|r|r|}
\hline & Value & \multicolumn{1}{|c|}{ df } & \multicolumn{1}{c|}{$\begin{array}{c}\text { Asymp. Sig. } \\
\text { (2-sided) }\end{array}$} \\
\hline Pearson Chi-Square & $11.106^{3}$ & 3 & .011 \\
Likelihood Ratio & 11.280 & 3 & .010 \\
N of Valid Cases & 230 & & \\
\hline
\end{tabular}

a. 2 cells $(25.0 \%)$ have expected count less than 5 .

The minimum expected count is 1.72 .

The greatest percentage of both males and females showed to the $2^{\text {nd }}$ premolar upon smile. The females however had a greater percentage of subjects revealing the $1^{\text {st }}$ molar. These differences are statistically significant $\left(\chi_{(1)}^{2}=11.106, p=0.01\right)$. A Fisher's Exact test was needed for this data since $25 \%$ of the cells had an expected count less than 5. Fisher's Exact test produced a p-value of 0.0083 . These results are displayed in table 5 and figure 12. 
Table 6. Comparison of buccal corridor between males and females.

\section{Group Statistics}

\begin{tabular}{|l|l|r|r|r|c|}
\hline & female & $\mathrm{N}$ & Mean & Std. Deviation & $\begin{array}{c}\text { Std. Error } \\
\text { Mean }\end{array}$ \\
\hline BuccalCorridor & 0 & 99 & .8778 & .03770 & .00379 \\
Buccal Corridor & 1 & 131 & .9008 & .03777 & .00330 \\
\hline
\end{tabular}

Independent Samples Test

\begin{tabular}{|c|c|c|c|c|c|c|c|c|c|c|}
\hline & & \multicolumn{2}{|c|}{$\begin{array}{l}\text { Levene's } \\
\text { Test for } \\
\text { Equality of } \\
\text { Variances }\end{array}$} & \multicolumn{7}{|c|}{ t-test for Equality of Means } \\
\hline & & \multirow[b]{2}{*}{$\mathrm{F}$} & \multirow[b]{2}{*}{ Sig. } & \multirow[b]{2}{*}{$\mathrm{t}$} & \multirow[b]{2}{*}{ df } & \multirow{2}{*}{$\begin{array}{l}\text { Sig. (2- } \\
\text { tailed) }\end{array}$} & \multirow{2}{*}{$\begin{array}{c}\text { Mean } \\
\text { Differen } \\
\text { ce }\end{array}$} & \multirow{2}{*}{$\begin{array}{c}\text { Std. } \\
\text { Error } \\
\text { Differen } \\
\text { ce }\end{array}$} & \multicolumn{2}{|c|}{$\begin{array}{c}95 \% \\
\text { Confidence } \\
\text { Interval of the } \\
\text { Difference }\end{array}$} \\
\hline & & & & & & & & & Lower & Upper \\
\hline $\begin{array}{l}\text { BuccalCorrid } \\
\text { or Buccal } \\
\text { Corridor }\end{array}$ & $\begin{array}{l}\text { Equal } \\
\text { variances } \\
\text { assumed } \\
\text { Equal } \\
\text { variances } \\
\text { not assumed }\end{array}$ & 016 & .899 & $\begin{array}{r}4.58 \\
9 \\
4.59 \\
0\end{array}$ & $\begin{array}{r}228 \\
211.3 \\
53\end{array}$ & .000 & $\begin{array}{l}-.02306 \\
-.02306\end{array}$ & $\begin{array}{l}.00503 \\
.00502\end{array}$ & $\begin{array}{r}.0329 \\
6 \\
-- \\
.0329 \\
7 \\
\end{array}$ & $\begin{array}{r}.0131 \\
6 \\
.0131 \\
6 \\
\end{array}$ \\
\hline
\end{tabular}

The average buccal corridor for males $(\mathrm{n}=99)$ was $12.3 \%(\mathrm{SD}=3.77 \%)$ and for females $(\mathrm{n}=131)$ it was $10 \%(\mathrm{SD}=3.77 \%)$. This difference between males and females is statistically significant $(\mathrm{t}(228)=4.589, \mathrm{p}=0.000)$. These results are displayed in table 6 and figure 13. 
Table 7. Comparison of smile arc between orthodontically treated and non-treated.

\begin{tabular}{|c|c|c|c|c|c|c|}
\hline \multicolumn{7}{|c|}{ Crosstab } \\
\hline & & & & \multicolumn{2}{|c|}{ OrthoTx Ortho Tx } & \multirow[b]{2}{*}{ Total } \\
\hline & & & & 1 no & 2 yes & \\
\hline \multirow{6}{*}{$\begin{array}{l}\text { SmileArc } \\
\text { Smile Arc }\end{array}$} & 1 reverse & Count & & 14 & 10 & 24 \\
\hline & & $\%$ within OrthoTx & Ortho Tx & $19.2 \%$ & $6.4 \%$ & $10.4 \%$ \\
\hline & 2 flat & Count & & 35 & 78 & 113 \\
\hline & & $\%$ within OrthoTx & Ortho Tx & $47.9 \%$ & $49.7 \%$ & $49.1 \%$ \\
\hline & 3 parallel & Count & & 24 & 69 & 93 \\
\hline & & $\%$ within OrthoTx & Ortho Tx & $32.9 \%$ & $43.9 \%$ & $40.4 \%$ \\
\hline \multirow[t]{2}{*}{ Total } & & Count & & 73 & 157 & 230 \\
\hline & & $\%$ within OrthoTx & Ortho Tx & $100.0 \%$ & $100.0 \%$ & $100.0 \%$ \\
\hline
\end{tabular}

\section{Chi-Square Tests}

\begin{tabular}{|l|r|r|r|}
\hline & \multicolumn{1}{|c|}{ Value } & \multicolumn{1}{c|}{ df } & \multicolumn{1}{c|}{$\begin{array}{c}\text { Asymp. Sig. } \\
\text { (2-sided) }\end{array}$} \\
\hline Pearson Chi-Square & $9.376^{\mathrm{a}}$ & 2 & .009 \\
Likelihood Ratio & 8.768 & 2 & .012 \\
Linear-by-Linear & 6.758 & 1 & .009 \\
Association & 230 & & \\
N of Valid Cases & & \\
\hline
\end{tabular}

a. 0 cells $(.0 \%)$ have expected count less than 5 . The minimum expected count is 7.62 .

The orthodontically treated group $(\mathrm{n}=157)$ had $6.4 \%$ reverse smile arc, $49.7 \%$ flat, and $43.9 \%$ parallel smile arc. The non-treated group $(n=73)$ had $19.2 \%$ reverse, $47.9 \%$ flat, and $32.9 \%$ parallel smile arc. These differences between the smile arcs in orthodontically treated and non-treated groups are statistically significant $\left(\chi_{(1)}^{2}=\right.$ 9.376, $\mathrm{p}=0.009$ ). These results are displayed in table 7 and figure 14 . 
Table 8. Comparison of buccal corridor between RME and non-expanded groups.

\section{Group Statistics}

\begin{tabular}{|ll|r|r|r|c|}
\hline & Expansion & \multicolumn{1}{|c|}{$\mathrm{N}$} & Mean & Std. Deviation & $\begin{array}{c}\text { Std. Error } \\
\text { Mean }\end{array}$ \\
\hline BuccalCorridor & 1 no & 160 & .8851 & .03790 & .00300 \\
Buccal Corridor & 2 yes & 70 & .9043 & .03962 & .00474 \\
\hline
\end{tabular}

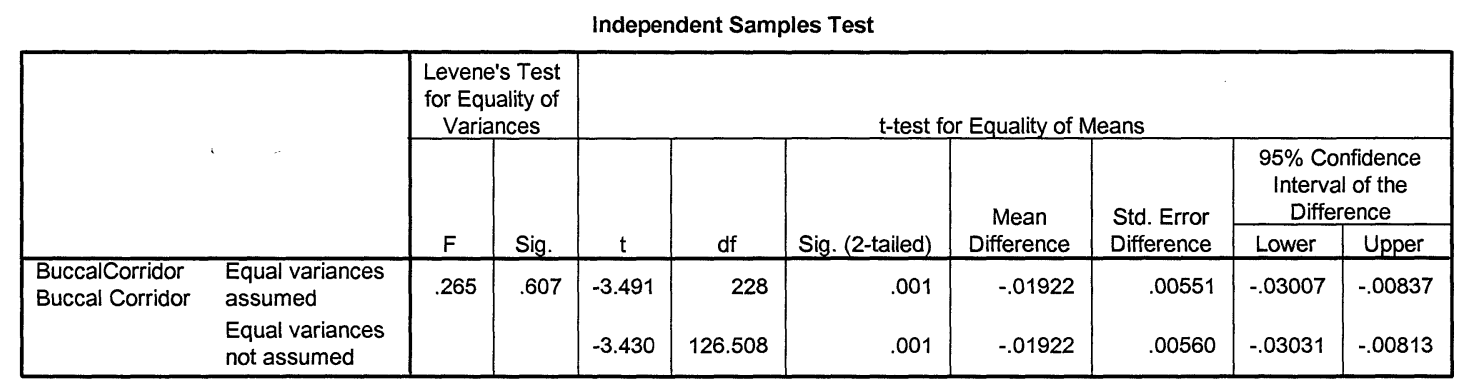

The average buccal corridor for the rapid maxillary expanded group $(n=70)$ was $9.6 \%$ with a standard deviation of $3.96 \%$ and a range of $2 \%$ to $19 \%$. The average buccal corridor for the non-expanded group $(\mathrm{n}=160)$ was $11.5 \%$ with a standard deviation of $3.79 \%$ and a range of $4 \%$ to $24 \%$. The difference between the two groups is statistically significant $(\mathrm{t}[228]=-3.491, \mathrm{p}=0.001)$. These results are displayed in table 8 and figure 15. 
Table 9. Univariate analysis of variance comparing buccal corridor between RME and non-expanded groups, controlling for gender differences.

\section{Univariate Analysis of Variance}

Between-Subjects Factors

\begin{tabular}{|ll|r|}
\hline & & \multicolumn{1}{|c|}{$N$} \\
\hline expanded & 0 & 160 \\
& 1 & 70 \\
female & 0 & 99 \\
& 1 & 131 \\
\hline
\end{tabular}

\section{Descriptive Statistics}

Dependent Variable: BuccalCorridor Buccal Corridor

\begin{tabular}{|ll|l|r|r|}
\hline expanded & female & Mean & Std. Deviation & \multicolumn{1}{|c|}{$\mathrm{N}$} \\
\hline 0 & 0 & .8722 & .03563 & 78 \\
& 1 & .8973 & .03607 & 82 \\
& Total & .8851 & .03790 & 160 \\
\hline 1 & 0 & .8986 & .03877 & 21 \\
& 1 & .9067 & .04012 & 49 \\
& Total & .9043 & .03962 & 70 \\
\hline Total & 0 & .8778 & .03770 & 99 \\
& 1 & .9008 & .03777 & 131 \\
& Total & .8909 & .03936 & 230 \\
\hline
\end{tabular}

Tests of Between-Subjects Effects

Dependent Variable: BuccalCorridor Buccal Corridor

\begin{tabular}{|l|r|r|r|r|l|}
\hline Source & $\begin{array}{c}\text { Type III Sum } \\
\text { of Squares }\end{array}$ & \multicolumn{1}{c|}{ df } & Mean Square & \multicolumn{1}{|c|}{ F } & Sig. \\
\hline Corrected Model & $.041^{\mathrm{a}}$ & 2 & .021 & 14.890 & .000 \\
Intercept & 149.153 & 1 & 149.153 & 107974.501 & .000 \\
expanded & .011 & 1 & .011 & 8.070 & .005 \\
female & .023 & 1 & .023 & 16.754 & .000 \\
Error & .314 & 227 & .001 & & \\
Total & 182.912 & 230 & & & \\
Corrected Total & .355 & 229 & & & \\
\hline
\end{tabular}

a. $\mathrm{R}$ Squared $=.116$ (Adjusted $\mathrm{R}$ Squared $=.108$ ) 
Parameter Estimates

Dependent Variable: BuccalCorridor Buccal Corridor

\begin{tabular}{|l|r|r|r|r|r|r|}
\hline & & & & & \multicolumn{2}{|c|}{ 95\% Confidence Interval } \\
\cline { 5 - 7 } Parameter & \multicolumn{1}{|c|}{$\mathrm{B}$} & Std. Error & $\mathrm{t}$ & \multicolumn{1}{c|}{ Sig. } & Lower Bound & Upper Bound \\
\hline Intercept & .910 & .005 & 194.076 & .000 & .901 & .920 \\
[expanded=0] & -.015 & .005 & -2.841 & .005 & -.026 & -.005 \\
[expanded=1] & $0^{\mathrm{a}}$ &. &. &. &. &. \\
[female=0] & -.021 & .005 & -4.093 & .000 & -.030 & -.011 \\
[female=1] & $0^{\mathrm{a}}$ &. &. &. &. &. \\
\hline
\end{tabular}

a. This parameter is set to zero because it is redundant.

\section{Estimated Marginal Means}

\section{1. expanded}

Dependent Variable: BuccalCorridor Buccal Corridor

\begin{tabular}{|l|r|r|r|r|}
\hline \multirow{2}{*}{ expanded } & & & \multicolumn{2}{|c|}{ 95\% Confidence Interval } \\
\cline { 4 - 5 } & Mean & Std. Error & Lower Bound & Upper Bound \\
\hline 0 & .885 & .003 & .879 & .891 \\
1 & .900 & .005 & .891 & .909 \\
\hline
\end{tabular}

\section{2. female}

Dependent Variable: BuccalCorridor Buccal Corridor

\begin{tabular}{|l|r|r|r|r|}
\hline & & & \multicolumn{2}{|c|}{$95 \%$ Confidence Interval } \\
\cline { 4 - 5 } female & Mean & Std. Error & Lower Bound & Upper Bound \\
\hline 0 & .882 & .004 & .874 & .890 \\
1 & .903 & .003 & .896 & .909 \\
\hline
\end{tabular}

After adjusting for $70 \%$ females in the rapid maxillary expansion group $(\mathrm{n}=70)$. The average buccal corridor for males $(\mathrm{n}=99)$ was $12.3 \%(\mathrm{SD}=3.77 \%)$ and for females $(\mathrm{n}=131)$ it was $10 \%(\mathrm{SD}=3.77 \%)$. This difference, after co-varying out gender, between the rapid maxillary expansion group and non-expanded is statistically significant $\quad(F(1,2)=14.89, p=0.000)$. 
Table 10. Comparison of most posterior maxillary tooth visible between RME and non-expanded groups.

\begin{tabular}{|l|c|c|r|r|r|r|}
\hline \multicolumn{1}{|c|}{ Case Processing Summary } \\
\cline { 2 - 8 } & \multicolumn{2}{|c|}{ Valid } & \multicolumn{2}{c|}{ Missing } & \multicolumn{2}{c|}{ Total } \\
\cline { 2 - 7 } & $\mathrm{N}$ & Percent & $\mathrm{N}$ & Percent & $\mathrm{N}$ & Percent \\
\hline $\begin{array}{l}\text { MostPosteriorTooth } \\
\text { Most Posterior } \\
\text { Tooth * Expansion }\end{array}$ & 230 & $100.0 \%$ & 0 & $.0 \%$ & 230 & $100.0 \%$ \\
\hline
\end{tabular}

\begin{tabular}{|c|c|c|c|c|c|}
\hline & & & \multicolumn{2}{|c|}{ Expansion } & \multirow[b]{2}{*}{ Total } \\
\hline & & & 1 no & 2 yes & \\
\hline \multirow{8}{*}{$\begin{array}{l}\text { MostPosteriorTooth } \\
\text { Most Posterior } \\
\text { Tooth }\end{array}$} & 3 canine & Count & 4 & 0 & 4 \\
\hline & & $\%$ within Expansion & $2.5 \%$ & $.0 \%$ & $1.7 \%$ \\
\hline & 4 1st premolar & Count & 33 & 17 & 50 \\
\hline & & $\%$ within Expansion & $20.6 \%$ & $24.3 \%$ & $21.7 \%$ \\
\hline & 5 2nd premolar & Count & 73 & 44 & 117 \\
\hline & & $\%$ within Expansion & $45.6 \%$ & $62.9 \%$ & $50.9 \%$ \\
\hline & 6 1st molar & Count & 50 & 9 & 59 \\
\hline & & $\%$ within Expansion & $31.3 \%$ & $12.9 \%$ & $25.7 \%$ \\
\hline \multirow{2}{*}{\multicolumn{2}{|c|}{ Total }} & Count & 160 & 70 & 230 \\
\hline & & $\%$ within Expansion & $100.0 \%$ & $100.0 \%$ & $100.0 \%$ \\
\hline
\end{tabular}

\section{Chi-Square Tests}

\begin{tabular}{|l|r|r|r|}
\hline & \multicolumn{1}{|c|}{ Value } & \multicolumn{1}{c|}{ df } & \multicolumn{1}{c|}{$\begin{array}{c}\text { Asymp. Sig. } \\
\text { (2-sided) }\end{array}$} \\
\hline Pearson Chi-Square & $11.315^{\mathrm{a}}$ & 3 & .010 \\
Likelihood Ratio & 13.238 & 3 & .004 \\
Linear-by-Linear & 2.595 & 1 & .107 \\
Association & 230 & & \\
N of Valid Cases & & \\
\hline
\end{tabular}

a. 2 cells $(25.0 \%)$ have expected count less than 5 . The minimum expected count is 1.22 .

The greatest percentage of most posterior maxillary visible tooth in both the rapid maxillary expanded and non-expanded was the maxillary $2^{\text {nd }}$ premolar. No subjects in the RME group displayed canines as the most posterior visible tooth, $2.5 \%$ of the nonexpanded group did however. The non-expanded group showed a larger percentage of subjects exhibiting $1^{\text {st }}$ maxillary molars upon smile. The difference between these groups is statistically significant $\left(\chi_{(1)}^{2}=11.315, \mathrm{p}=0.01\right)$. These results are displayed in table 10 and figure 16. 
Table 11. Anterior smile height relationship with smile arc.

\section{Crosstab}

\begin{tabular}{|c|c|c|c|c|c|c|}
\hline & \multicolumn{3}{|c|}{ SmileArc Smile Arc } & \multirow[b]{2}{*}{ Total } \\
\hline & & & 1 reverse & 2 flat & 3 parallel & \\
\hline \multirow{6}{*}{$\begin{array}{l}\text { AnteriorHeight } \\
\text { Anterior Height }\end{array}$} & 1 low smile & Count & 7 & 25 & 18 & 50 \\
\hline & & $\begin{array}{l}\% \text { within SmileArc } \\
\text { Smile Arc }\end{array}$ & $29.2 \%$ & $22.1 \%$ & $19.4 \%$ & $21.7 \%$ \\
\hline & 2 average smile & Count & 14 & 63 & 54 & 131 \\
\hline & & $\begin{array}{l}\text { \% within SmileArc } \\
\text { Smile Arc }\end{array}$ & $58.3 \%$ & $55.8 \%$ & $58.1 \%$ & $57.0 \%$ \\
\hline & 3 high smile & Count & 3 & 25 & 21 & 49 \\
\hline & & $\begin{array}{l}\text { \% within SmileArc } \\
\text { Smile Arc }\end{array}$ & $12.5 \%$ & $22.1 \%$ & $22.6 \%$ & $21.3 \%$ \\
\hline \multirow[t]{2}{*}{ Total } & & Count & 24 & 113 & 93 & 230 \\
\hline & & $\begin{array}{l}\% \text { within SmileArc } \\
\text { Smile Arc }\end{array}$ & $100.0 \%$ & $100.0 \%$ & $100.0 \%$ & $100.0 \%$ \\
\hline
\end{tabular}

Chi-Square Tests

\begin{tabular}{|l|l|r|r|}
\hline & \multicolumn{1}{|c|}{ Value } & \multicolumn{1}{c|}{ df } & \multicolumn{1}{c|}{$\begin{array}{c}\text { Asymp. Sig. } \\
(2 \text {-sided) }\end{array}$} \\
\hline Pearson Chi-Square & $1.897^{a}$ & 4 & .755 \\
Likelihood Ratio & 1.999 & 4 & .736 \\
Linear-by-Linear & 1.280 & 1 & .258 \\
Association & 230 & & \\
N of Valid Cases & 230 \\
\hline
\end{tabular}

a. 0 cells $(.0 \%)$ have expected count less than 5 . The minimum expected count is 5.11 .

The relationship between the anterior smile height and smile arc is not statistically significant $\left(\chi_{(1)}^{2}=1.897, p=0.755\right)$. These results are displayed in table 11 and figure 17. 
Table 12. Posterior smile height relationship with smile arc.

\begin{tabular}{|c|c|c|c|c|c|c|}
\hline \multicolumn{7}{|c|}{ Crosstab } \\
\hline & & & \multicolumn{3}{|c|}{ SmileArc Smile Arc } & \multirow[b]{2}{*}{ Total } \\
\hline & & & 1 reverse & 2 flat & 3 parallel & \\
\hline \multirow{6}{*}{$\begin{array}{l}\text { PosteriorHeight } \\
\text { Posterior Height }\end{array}$} & 1 low smile & Count & 3 & 22 & 27 & 52 \\
\hline & & $\begin{array}{l}\% \text { within SmileArc } \\
\text { Smile Arc }\end{array}$ & $12.5 \%$ & $19.5 \%$ & $29.0 \%$ & $22.6 \%$ \\
\hline & 2 average smile & Count & 2 & 38 & 40 & 80 \\
\hline & & $\begin{array}{l}\% \text { within SmileArc } \\
\text { Smile Arc }\end{array}$ & $8.3 \%$ & $33.6 \%$ & $43.0 \%$ & $34.8 \%$ \\
\hline & 3 high smile & Count & 19 & 53 & 26 & 98 \\
\hline & & $\begin{array}{l}\% \text { within SmileArc } \\
\text { Smile Arc }\end{array}$ & $79.2 \%$ & $46.9 \%$ & $28.0 \%$ & $42.6 \%$ \\
\hline \multirow{2}{*}{\multicolumn{2}{|c|}{ Total }} & Count & 24 & 113 & 93 & 230 \\
\hline & & $\begin{array}{l}\% \text { within SmileArc } \\
\text { Smile Arc }\end{array}$ & $100.0 \%$ & $100.0 \%$ & $100.0 \%$ & $100.0 \%$ \\
\hline
\end{tabular}

\section{Chi-Square Tests}

\begin{tabular}{|c|c|c|c|}
\hline & Value & df & $\begin{array}{l}\text { Asymp. Sig. } \\
\text { (2-sided) }\end{array}$ \\
\hline Pearson Chi-Square & $22.658^{a}$ & 4 & .000 \\
\hline Likelihood Ratio & 23.882 & 4 & .000 \\
\hline $\begin{array}{l}\text { Linear-by-Linear } \\
\text { Association }\end{array}$ & 16.022 & 1 & .000 \\
\hline $\mathrm{N}$ of Valid Cases & 230 & & \\
\hline
\end{tabular}

a. 0 cells $(.0 \%)$ have expected count less than 5 . The minimum expected count is 5.43 .

The relationship between posterior smile height and smile arc is statistically significant $\left(\chi_{(1)}^{2}=22.658, \mathrm{p}=0.000\right)$. Of particular note, is the coincidence of high posterior smile height and reverse smile arc, where $79 \%$ of those with a reverse smile arc had a high posterior smile height. These results are displayed in table 12 and figure 18. 
Table 13. Comparison of anterior smile height between orthodontically treated and non-treated groups.

\begin{tabular}{|c|c|c|c|c|c|}
\hline \multicolumn{6}{|c|}{ Crosstab } \\
\hline & & & \multicolumn{2}{|c|}{ OrthoTx Ortho Tx } & \multirow[b]{2}{*}{ Total } \\
\hline & & & 1 no & 2 yes & \\
\hline \multirow{6}{*}{$\begin{array}{l}\text { AnteriorHeight } \\
\text { Anterior Height }\end{array}$} & 1 low smile & Count & 23 & 27 & 50 \\
\hline & & $\%$ within OrthoTx Ortho Tx & $31.5 \%$ & $17.2 \%$ & $21.7 \%$ \\
\hline & 2 average smile & Count & 40 & 91 & 131 \\
\hline & & $\%$ within OrthoTx Ortho Tx & $54.8 \%$ & $58.0 \%$ & $57.0 \%$ \\
\hline & 3 high smile & Count & 10 & 39 & 49 \\
\hline & & $\%$ within OrthoTx Ortho Tx & $13.7 \%$ & $24.8 \%$ & $21.3 \%$ \\
\hline \multirow[t]{2}{*}{ Total } & & Count & 73 & 157 & 230 \\
\hline & & $\%$ within OrthoTx Ortho Tx & $100.0 \%$ & $100.0 \%$ & $100.0 \%$ \\
\hline
\end{tabular}

\section{Chi-Square Tests}

\begin{tabular}{|l|r|r|r|}
\hline & \multicolumn{1}{|c|}{ Value } & \multicolumn{1}{c|}{ df } & \multicolumn{1}{c|}{$\begin{array}{c}\text { Asymp. Sig. } \\
\text { (2-sided) }\end{array}$} \\
\hline Pearson Chi-Square & $7.685^{\mathrm{a}}$ & 2 & .021 \\
Likelihood Ratio & 7.650 & 2 & .022 \\
Linear-by-Linear & 7.467 & 1 & .006 \\
Association & 230 & & \\
N of Valid Cases & & \\
\hline
\end{tabular}

a. 0 cells $(.0 \%)$ have expected count less than 5 . The minimum expected count is 15.55 .

The orthodontically treated group had a larger percentage of subjects displaying a high anterior smile height $(24.8 \%)$ compared to the non-treated $(13.7 \%)$. Whereas the nontreated had a much larger percentage exhibiting a low anterior smile height. The relationship between anterior smile height and orthodontic treatment is statistically significant $\left(\chi_{(1)}^{2}=7.685, p=0.021\right)$. These results are displayed in table 13 and figure 19. 
Table 14. Comparison of posterior smile height between orthodontically treated to non-treated groups.

\begin{tabular}{|lll|r|r|r|}
\multicolumn{9}{|c|}{ Crosstab } \\
\hline
\end{tabular}

\section{Chi-Square Tests}

\begin{tabular}{|l|l|r|r|}
\hline & Value & \multicolumn{1}{c|}{ df } & \multicolumn{1}{c|}{$\begin{array}{c}\text { Asymp. Sig. } \\
\text { (2-sided) }\end{array}$} \\
\hline Pearson Chi-Square & $4.320^{\mathrm{a}}$ & 2 & .115 \\
Likelihood Ratio & 4.373 & 2 & .112 \\
Linear-by-Linear & .221 & 1 & .639 \\
Association & 230 & & \\
N of Valid Cases & & \\
\hline
\end{tabular}

a. 0 cells $(.0 \%)$ have expected count less than 5 . The minimum expected count is 16.50 .

The relationship between posterior smile height and orthodontic treatment is not statistically significant $\left(\chi_{(1)}^{2}=4.320, p=0.115\right)$. These results are displayed in table 14 and figure 20. 
Three separate raters were employed to score the smile arc data because of its subjectivity. The different measurements can be seen in figure 21 . The kappa statistic was used to examine the agreement among the raters. A kappa score of 0.6639 was obtained. This correlates to "substantial" agreement among the multiple raters. 


\section{$\underline{\text { Discussion }}$}


This study is the first to provide dynamic norms for anterior smile height, smile arc parallelism, and most posterior maxillary tooth visualized. Also, this is the first time norms have been obtained for the buccal corridor ratio. Furthermore, a new measurement has been introduced, the posterior smile height, and subsequent dynamic norms for this new measurement.

The establishment of norms is important in orthodontic diagnoses and treatment planning. Traditionally, norms established in orthodontics have focused heavily upon profiles and the use of the lateral cephalometric radiograph. In this present study, frequencies were reported to help establish averages for different parameters of the smile. The only other studies that provide averages for smile components are by Tjan et al. (Tjan, Miller et al. 1984) and Dong et al. (Dong, Jin et al. 1999). Although these studies have been valuable as a spring board for future studies, they each have some drawbacks, which our current study sought to address. Both the Tjan et al. study and the Dong et al. study were done with static photographs. A disadvantage associated with the use of static photos rather than a dynamic medium is that traditional photos capture only one point in time. Video allows the examiner to look at roughly 30 frames per second as opposed to 1 single frame. Thus, multiple frames can be analyzed to find the best representation of the true smile. In addition, the Dong et al. study was carried out in a Korean population only. The exclusion of other ethnicities can greatly limit the utility of these norms for other groups or for the general population.

Tjan et al. (Tjan, Miller et al. 1984) and Dong et al. (Dong, Jin et al. 1999) both reported that the majority ( $68.9 \%$ and $56 \%$ respectively) displayed average ( $75 \%$ 
$-100 \%$ of central incisor) anterior smile height. Therefore, it was expected that similar results would be found dynamically. Our report of $56.9 \%$ for the anterior smile height is almost the exact same as found by Dong et al. (Dong, Jin et al. 1999). Our results for low anterior smile height of $21.7 \%$ mirrored those of Tjan et al. (Tjan, Miller et al. 1984) of 20.4\%, however differed from the $15 \%$ found by Dong et al. (Dong, Jin et al. 1999). Dong et al. (Dong, Jin et al. 1999) observed a high anterior smile height in $29 \%$, which is almost triple that found by Tjan et al. (Tjan, Miller et al. 1984) of $10.5 \%$. We found a high anterior smile height in between these two reports of $21.3 \%$. It can be concluded that our dynamic data for anterior smile height supports that found by Tjan et al. (Tjan, Miller et al. 1984) and Dong et al. (Dong, Jin et al. 1999).

No comparable study was found in the literature which looked at posterior smile height, therefore it cannot be compared to any previous norms. Isaacson (Isaacson 1992) does mention that "posterior maxillary teeth do contribute to esthetics of the smile" and that "gingival exposure at the molars is an as yet unexplored phenomena". In this present study it was found that more subjects showed a high posterior smile height (42.6\%) compared to average and low. This result may not be surprising; several reasons can explain this finding. Firstly, the anatomy of the smile itself could be an explanation. The center of the lip is often more inferior than the lateral aspects during a smile because of the thickness and shape of the philtrum. The philtrum is often referred to as having "cupid's bow" shape, where the center in directed inferiorly. The type of smile, where the lateral aspects of the lips raise more than the center is referred to as a "mona lisa" smile (Sarver and Ackerman 2000). 
Another reason why the highest percentage of subjects displayed a high posterior smile height could be due to the smile arc parallelism. There was a strong association found between a reverse smile arc and high posterior smile height; $79 \%$ of the subjects with a reverse smile arc displayed a high posterior smile height. The next highest percentage of those showing high posterior smile height was the flat smile arc group, $46.9 \%$ of the flat smile arc group showed a high posterior smile height. Thus, it can hypothesized that for whatever reason one has a reverse or flat smile arc (potential reasons could include over eruption of the maxillary posterior teeth, vertical maxillary excess, and others), they will likely show more posterior gingiva upon smiling. Therefore, since $59 \%$ of the sample had either reverse or flat smile arc it is not surprising that more subjects displayed a high posterior smile height than average or low posterior smile heights.

In this study, we found that a flat smile arc was the most frequent observation for the relationship of the maxillary incisal edges and cusp tips with the lower lip. Approximately half (49\%) of the total sample had a flat smile arc. This is in disagreement with that found by Tjan et al. (Tjan, Miller et al. 1984) and Dong et al. (Dong, Jin et al. 1999). They both found parallel to be the most frequent observation for the smile arc. Tjan et al. (Tjan, Miller et al. 1984) found that the overwhelming majority (84.8\%) had a parallel smile; Dong et al. found less but still the majority, with $60 \%$ parallel. Our results could differ for a number of reasons. Dynamic recording, as opposed to static observation, of the smile may actually produce a difference in the smile obtained for measurement. The measurement of the smile arc is a somewhat subjective measurement. Great care was taken to keep the 
measurement and data gathering process as standardized and objective as possible. For example, before video recording, the subjects were advised to look straight forward as if they were looking at their eyes in the mirror. This was done to place the subjects in natural head position (Moorees CFA 1958) to standardize the data gathering.

Even when an individual is placed in perfect natural head position, the smile arc is still a subjective measurement. Therefore, to standardize the measurement process very specific instructions were followed on how to compare the parallelism of the smile arc to the lower lip. A line was envisioned that connected the incisal edges and cusp tips and this was compared to the curvature of the upper border of the lower lip. Furthermore, to increase the validity of the smile arc measurement, multiple uniformly trained raters were used. The variation observed between the different raters was relatively small. The kappa statistic (Elston and Johnson 1994) showed "substantial" agreement among the multiple raters.

Our results for the most posterior maxillary tooth visible showed that $51 \%$ of the sample displayed maxillary $2^{\text {nd }}$ premolars; Dong et al. (Dong, Jin et al. 1999) found similar results with $57 \%$ of their sample showing maxillary $2^{\text {nd }}$ premolars. These findings are different form Tjan et al. (Tjan, Miller et al. 1984) who found $49 \%$ showed only the maxillary $1^{\text {st }}$ premolar while only $41 \%$ demonstrated $2^{\text {nd }}$ premolars upon smiling. Our study found that only $22 \%$ of subjects showed $1^{\text {st }}$ premolars while smiling. A surprising result, which was not in agreement with either Dong et al. (Dong, Jin et al. 1999) or Tjan et al. (Tjan, Miller et al. 1984), was that $25 \%$ of the sample exhibited maxillary $1^{\text {st }}$ molars upon smile in this current study. Tjan et al. 
(Tjan, Miller et al. 1984) found only $4 \%$ exemplified maxillary $1^{\text {st }}$ molars upon smile. This is a notable difference, and one of the largest differences of all variables between this current study and those of Tjan et al. (Tjan, Miller et al. 1984) and Dong et al. (Dong, Jin et al. 1999). Neither Tjan et al. (Tjan, Miller et al. 1984) nor Dong et al. (Dong, Jin et al. 1999) described in detail how they gathered their data nor the lighting situation. In this present study however all video recording took place indoors with only ambient light, no supplemental light was directed into the mouth. This was done to emulate the everyday natural surroundings in which people's smiles are viewed. Therefore, there can be little argument made that artificial light caused more teeth to be visualized in the smile.

A statistically significant difference was found in the most posterior tooth visualized between RME and non-expanded groups. The non-expanded group had a larger percentage of subjects displaying the $1^{\text {st }}$ maxillary molar upon smile. The reason for this could be that as the maxilla is expanded the molars are moved transversely toward the cheeks and are therefore more apt to be hidden by the cheeks during the smile.

Similar to the posterior smile height, no norms for buccal corridor exist in the literature. In the recent study by Moore et al. (Moore, Southard et al. 2005), the same concept that was developed by the author, in which buccal corridor is represented by a percentage of the total smile width, was introduced By trial and error they developed and defined a range of buccal corridors and described them by the corresponding smile fullness. They defined a buccal corridor of $28 \%$ as medium-narrow, $15 \%$ buccal corridor as medium, $10 \%$ buccal corridor as medium-broad, and $2 \%$ buccal corridor as 
broad smile fullness (Moore, Southard et al. 2005). They were not too far off in comparison to the results we obtained for the buccal corridor. We found an average of $11.0 \%$ buccal corridor for the entire sample which would fall in between medium to medium broad smile fullness defined by Moore et al. They defined narrow smile fullness as $28 \%$ buccal corridor and we found the largest buccal corridor to be $24 \%$. In addition, they defined broad smile fullness at $2 \%$ buccal corridor, this is the upper limit of what we found in this current study, $2 \%$, which occurred in a rapid maxillary expanded subjects.

One of the main objectives of this study was to lend scientific evidence to begin an evidence based assessment of whether rapid maxillary expanded subjects display less buccal corridor than non-expanded subjects. We did find a statistically significant $(\mathrm{p}$ value $=0.001)$ difference in the size of the buccal corridor between rapid maxillary expanded (9.6\%) and non-expanded subjects (11.5\%). A limitation in the study design is that it is cross-sectional, and thereby correlative, thus cause and effect cannot be clearly established. However, there is no question that that the RME group showed less buccal corridor than the non-expanded group. Therefore, scientific evidence now exists that at least establishes a possible link between rapid maxillary expansion and a smaller buccal corridor.

Another primary objective of this study was to use video to further examine the work of Ackerman(Ackerman, Ackerman et al. 1998) comparing the smile arc of orthodontically treated versus non-treated. We found quite different results than Ackerman(Ackerman, Ackerman et al. 1998). He observed orthodontically treated smile arcs to be more flat than the non-treated smiles. In contrast, we found the 
orthodontically treated group showed a greater percentage of parallel smile arcs compared to the non-treated group. Differences between our study and Ackerman's(Ackerman, Ackerman et al. 1998) were that our data was gathered dynamically and we had a much larger sample than that of Ackerman's, 230 versus 30 subjects. Our data does not support the recent hypothesis that orthodontic treatment flattens the smile arc.

Another objective was to compare the smile components between males and females. We found a statistically significant difference between males and females in every smile component analyzed. Peck and Peck (Peck and Peck 1995) have established that females display a higher anterior smile line than males. Our dynamic results support those of Peck and Peck (Peck and Peck 1995). Furthermore, we found females display a higher posterior smile height compared to males. Females also showed a higher percentage of parallel smile arc; males showed a higher percentage of reverse smile arc. Moreover, we found females display less buccal corridor than males.

A difference also worth noting was that of the anterior smile height between orthodontically treated and non-treated subjects. Of the orthodontically treated, $24.8 \%$ showed a high anterior smile height versus the non-treated group, in which only $13.7 \%$ displayed a high anterior smile height. Additionally, 31.5\% of the non-treated group showed a low anterior smile height, whereas in the orthodontically treated only $17.2 \%$ showed a low anterior smile height. Could this difference be from the orthodontic treatment itself? An argument can be proposed that the non-treated subjects do not 
feel as confident about their smiles and therefore have adapted to showing less of their teeth during the smile.

In summary, this study aimed to use video capture to establish norms for different smile components. We found females have higher anterior and posterior smile heights, more parallel smile arc, have a higher frequency of exhibiting $1^{\text {st }}$ molars, and display less buccal corridor. It was also shown that orthodontically treated subjects showed a higher frequency of parallel smile arc compared to the non-treated group. This finding does not support the previous studies of this nature.

In addition, we found that the RME group displayed less buccal corridor upon smile compared to the non-expanded. This evidence supports the prevailing opinion, that RME therapy decreases the buccal corridor 
Conclusion 
Norms have been dynamically introduced for different components of the smile. The majority of subjects in the total sample displayed upon smile: average anterior smile height, high posterior smile height, a flat smile arc, to the $2 \mathrm{nd}$ maxillary premolar, and $11 \%$ buccal corridor.

Females, as a group, showed upon smile a higher anterior and posterior smile height, more parallel smile arc, more posterior teeth, and less buccal corridor than males. The Orthodontically treated group had a statistically significant more parallel smile arc compared to the non-treated group, therefore it can be argued that orthodontic treatment may not flatten the smile arc.

The rapid maxillary expansion group showed statistically significant less buccal corridor upon smile. This introduces evidence in the literature in support of the long standing claim that RME is associated with a smaller buccal corridor. The RME group did show a statistically significant difference in most posterior maxillary tooth visible compared to the non-expanded group. However, the RME group did not show more posterior teeth than the non-expanded, they showed less.

The coincidence of a high posterior smile height and a reverse smile arc is statistically significant. There may be a causal relationship in effect between these two parameters.

The orthodontically treated group showed a higher anterior smile height compared to the non-treated. This poses further questions as to whether this is caused by the orthodontic treatment itself or the subjects' willingness to fully smile without orthodontic treatment. 


\section{$\underline{\text { Figures }}$}


(a)

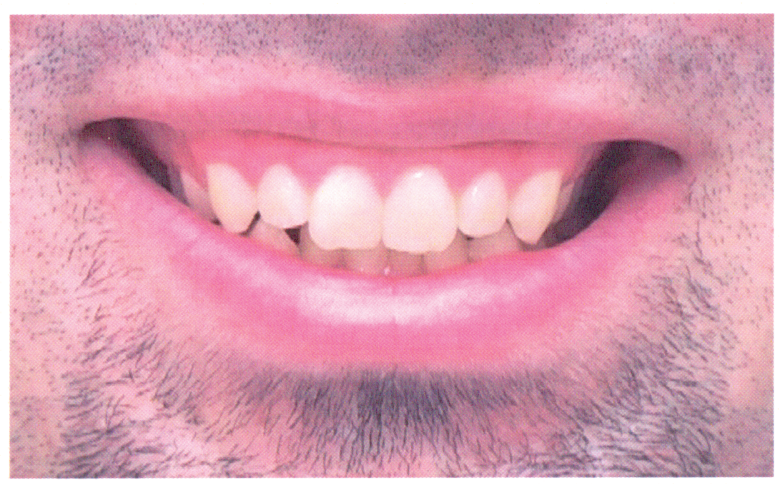

(b)

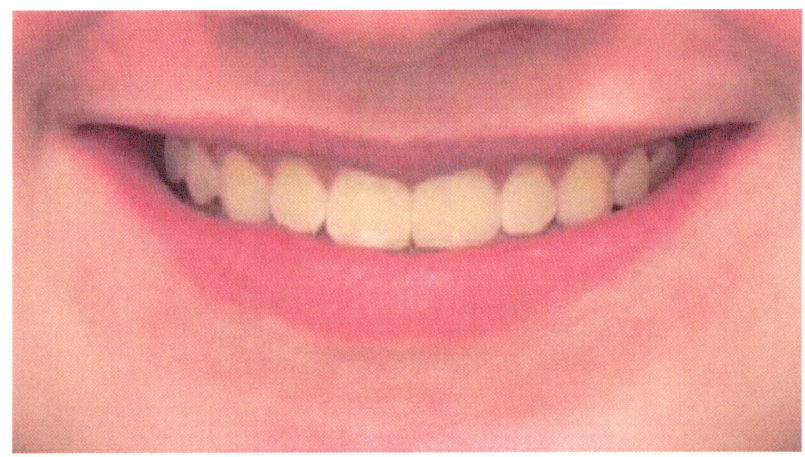

(c)

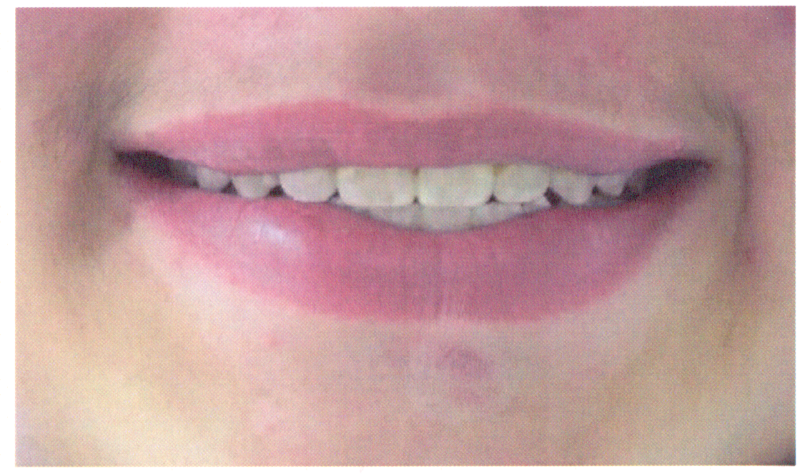

Figure 1.

Examples of Anterior and Posterior Smile

Heights

a. high, b. average, c. low 
(a)

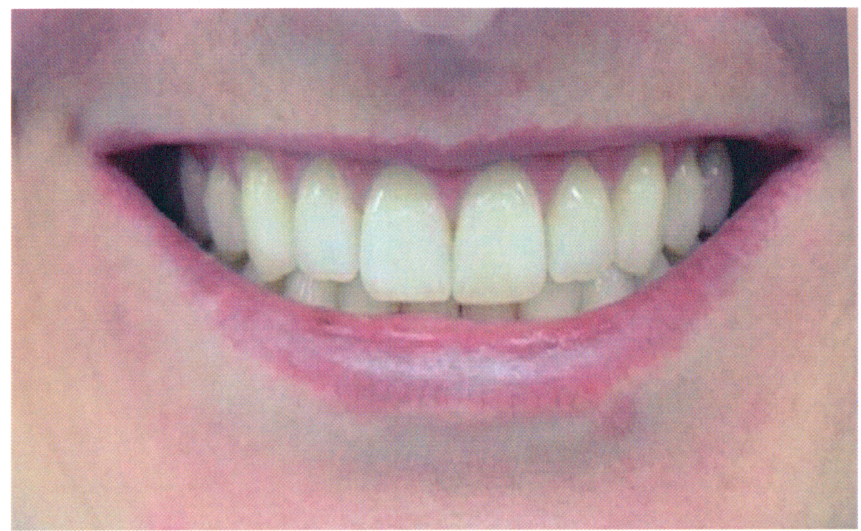

(b)

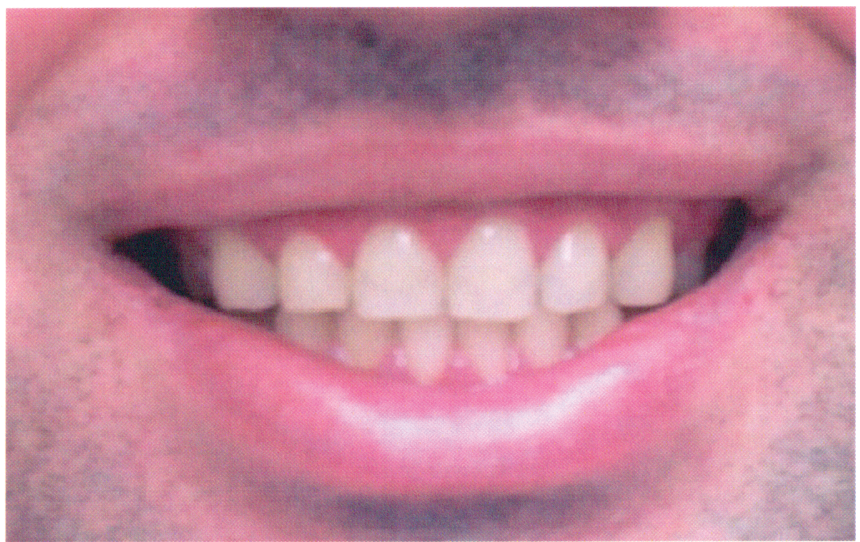

(c)

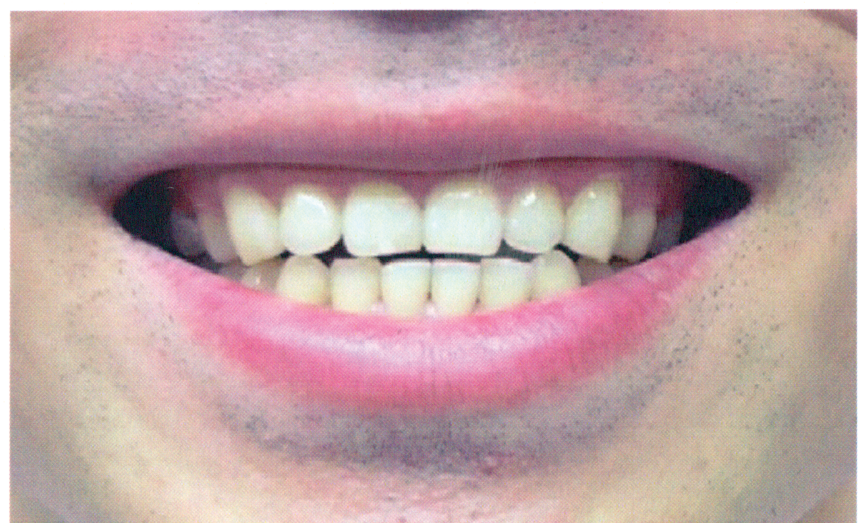

Figure 2.

Examples of Smile Arc

a. parallel, b. flat c. reverse 
(a)

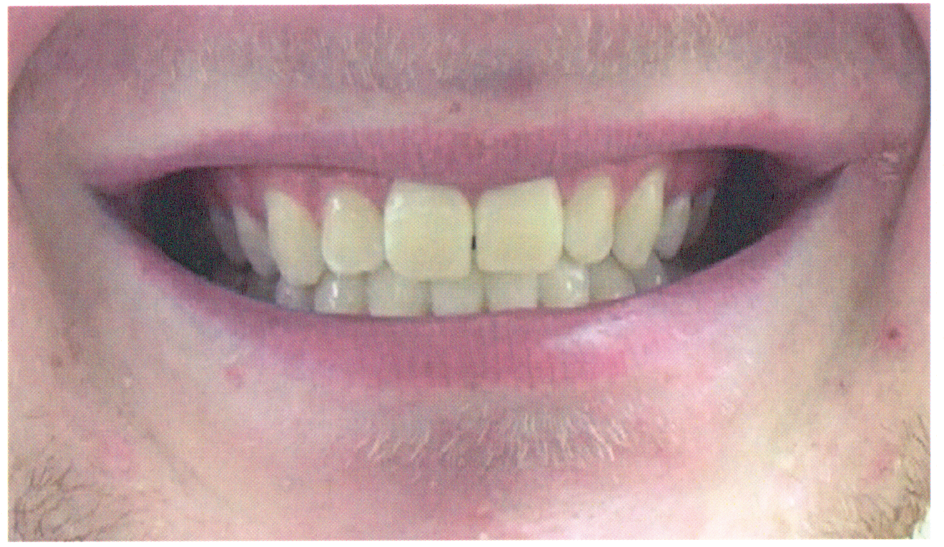

(b)

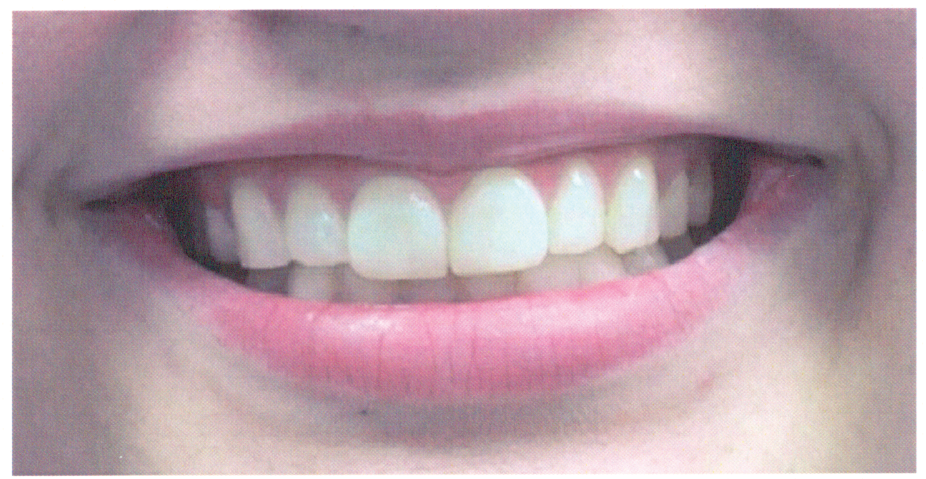

(c)

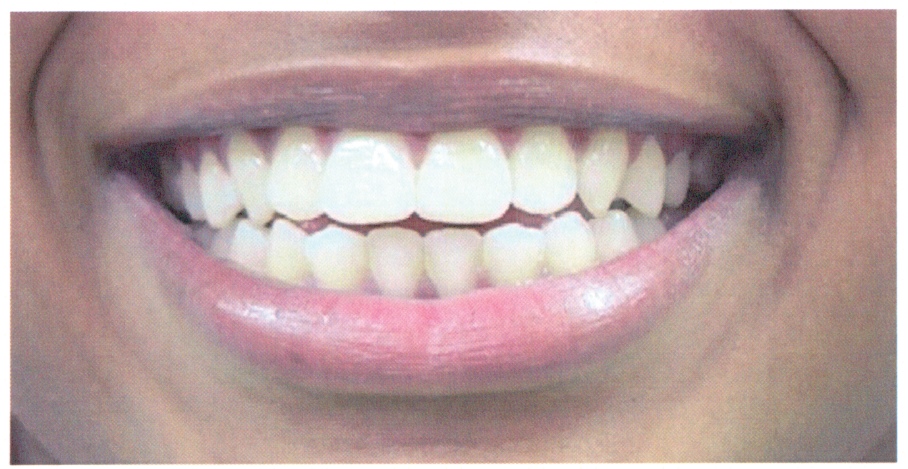

Figure 3.

Examples of different Buccal Corridor sizes.

a. large (18\%), b. average (12\%), c. small (2\%) 
(a)

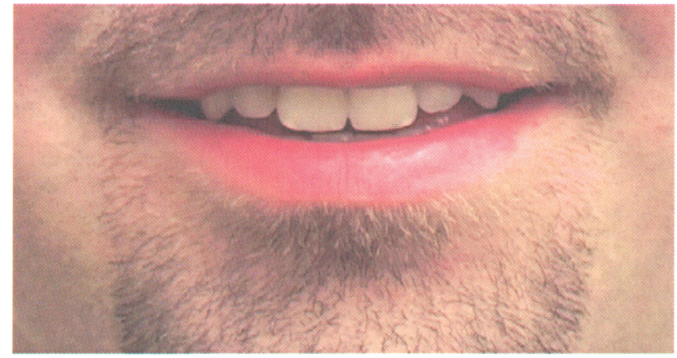

(b)

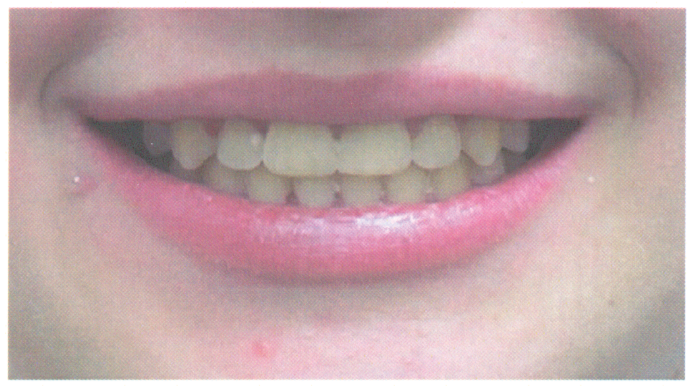

(c)

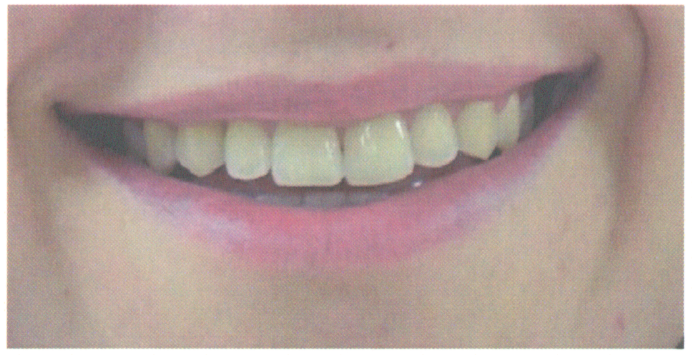

(d)

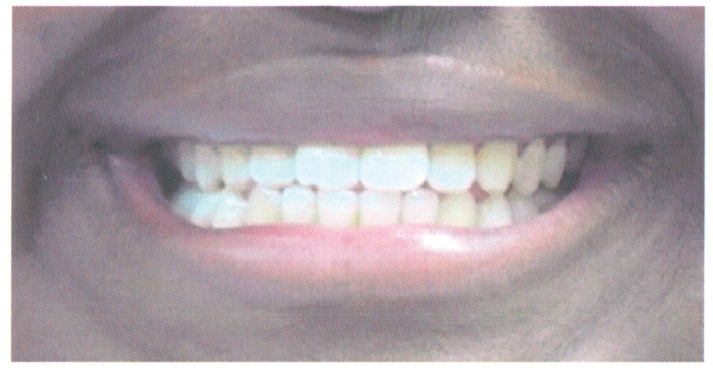

Figure 4.

Examples of Most Posterior Maxillary Tooth Visible.

(a) canine, (b) $1^{\text {st }}$ premolar, (c) $2^{\text {nd }}$ premolar, (d) $1^{\text {st }}$ molar 


\section{Anterior Smile Height}

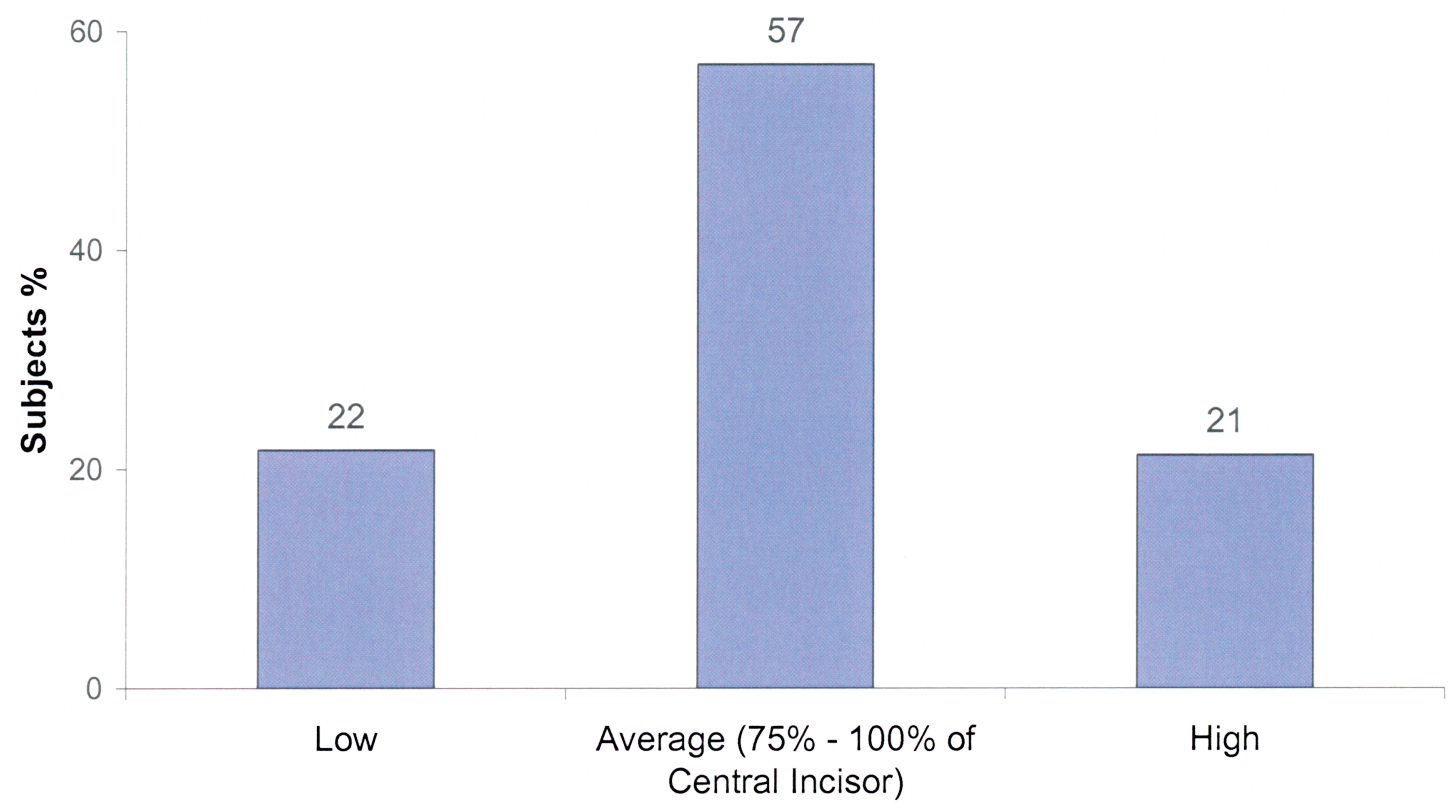

Figure 5. Frequencies for anterior smile height for the total sample $(\mathrm{n}=230)$. 


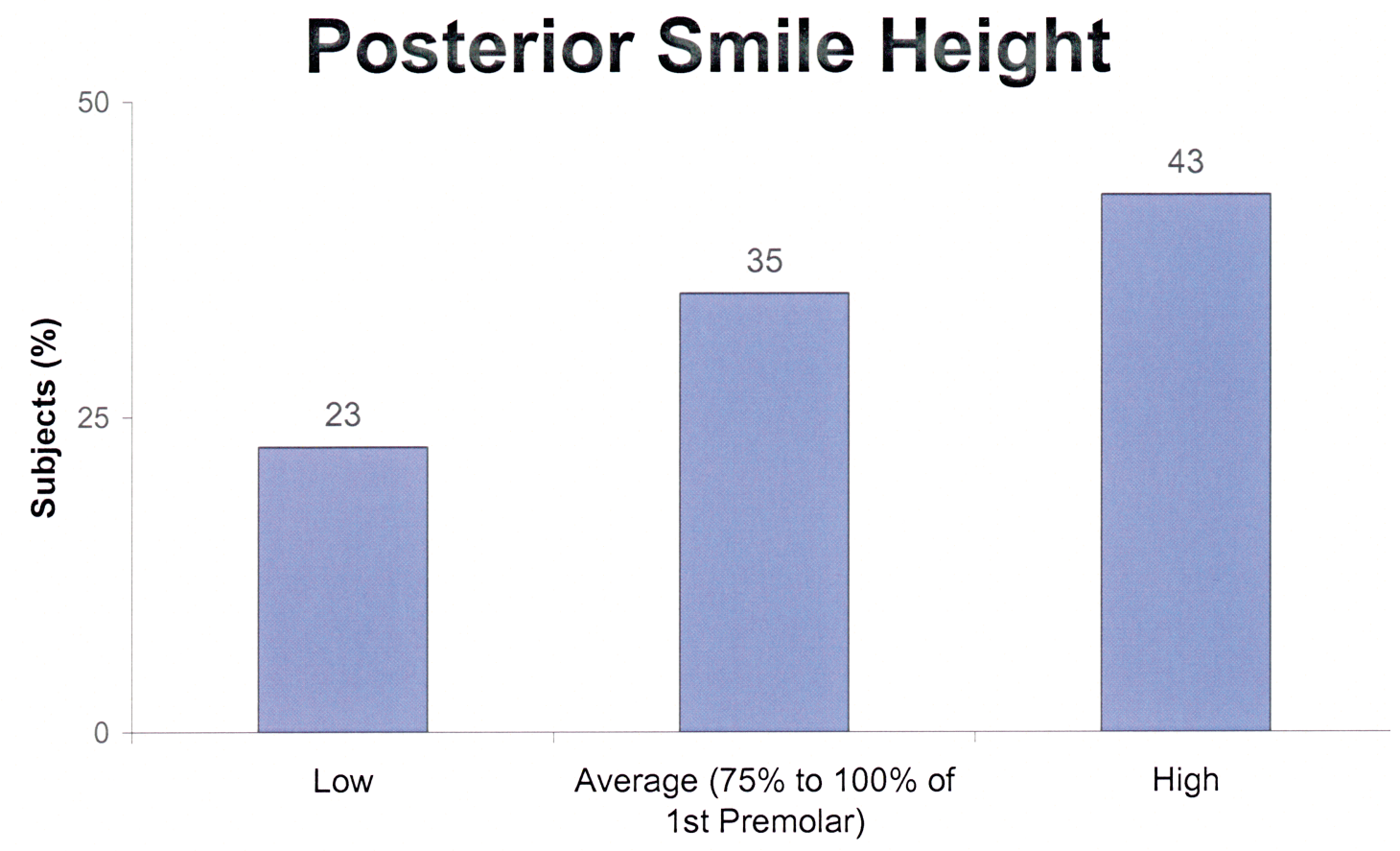

Figure 6. Frequencies for posterior smile height for the total sample $(n=230)$. 


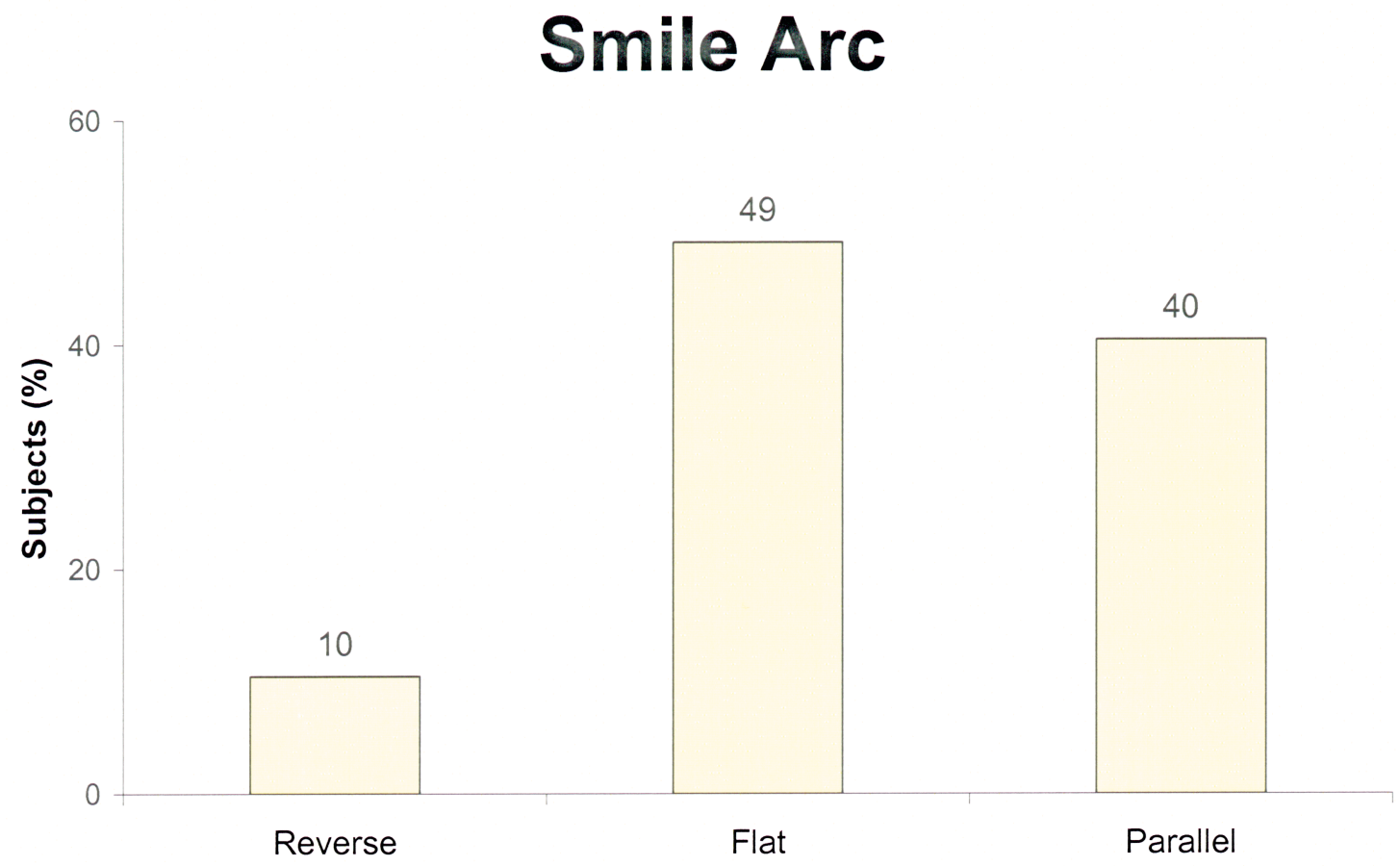

Figure 7. Frequencies for smile arc for the total sample $(n=230)$. 


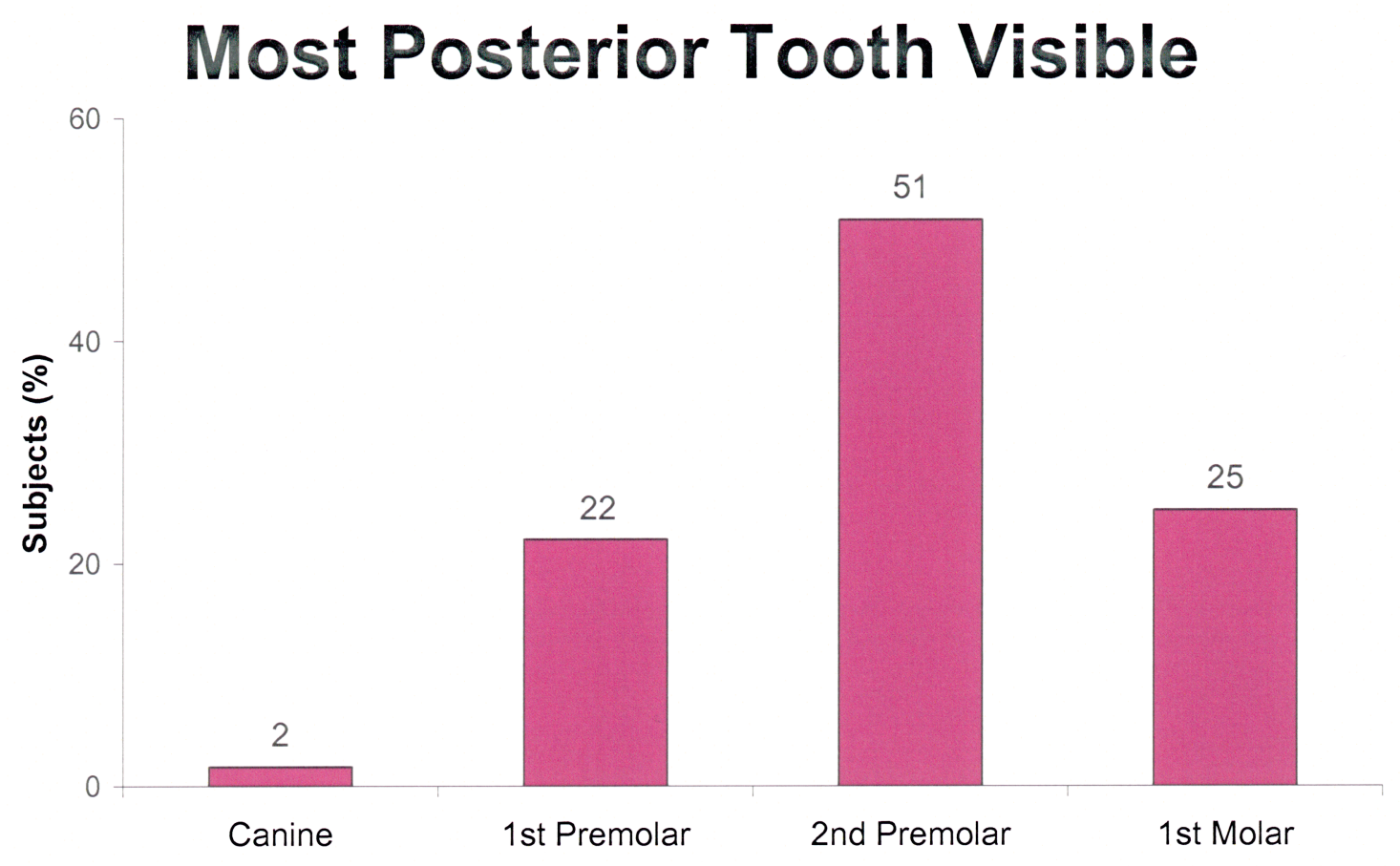

Figure 8. Frequencies for the most posterior maxillary tooth visible for the total sample $(n=230)$. 


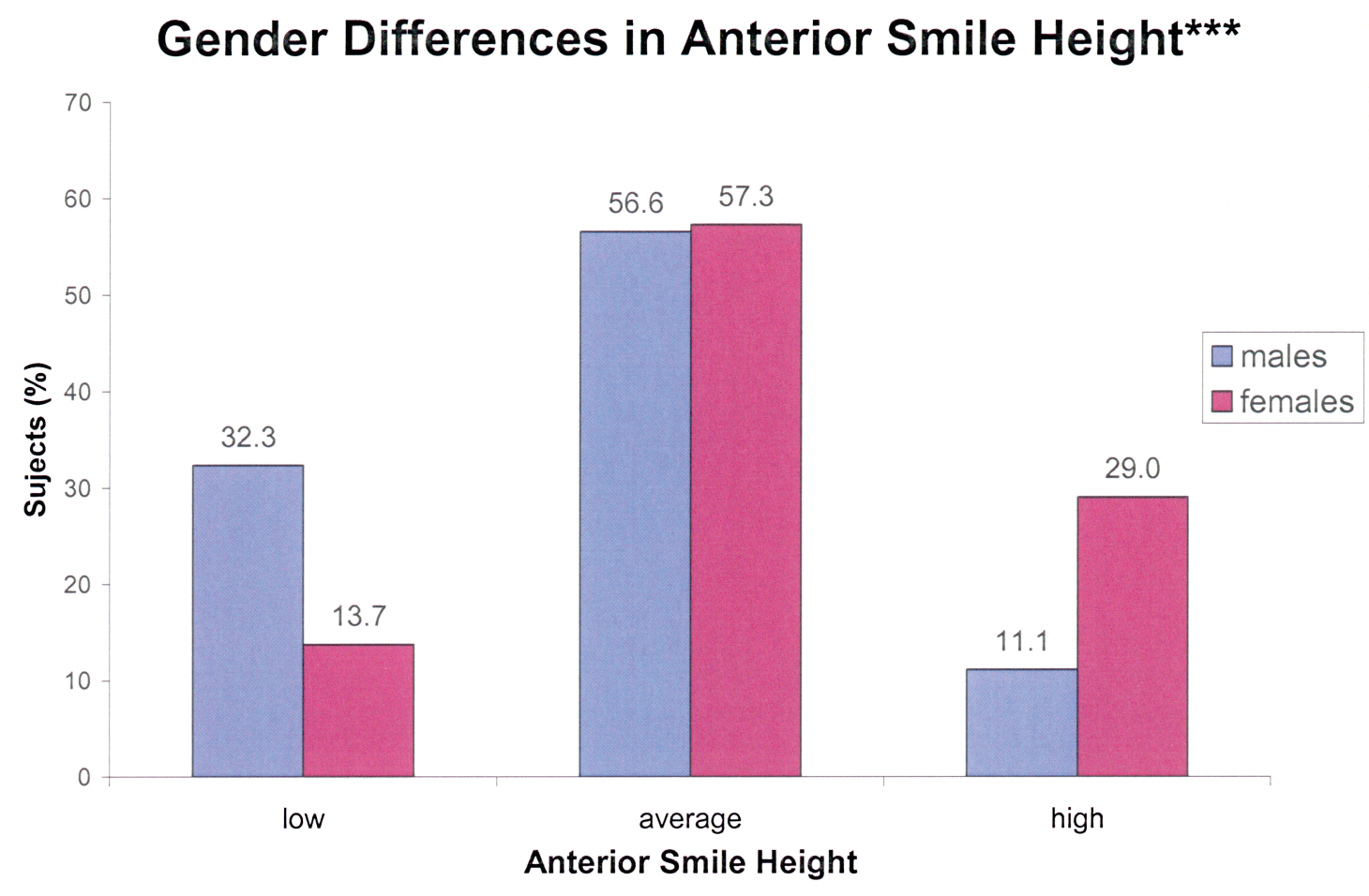

Figure 9. Comparison of the anterior smile height between males $(\mathrm{n}=99)$ and females $(\mathrm{n}=131) .{ }^{*} * * \mathrm{p}>0.001$ 


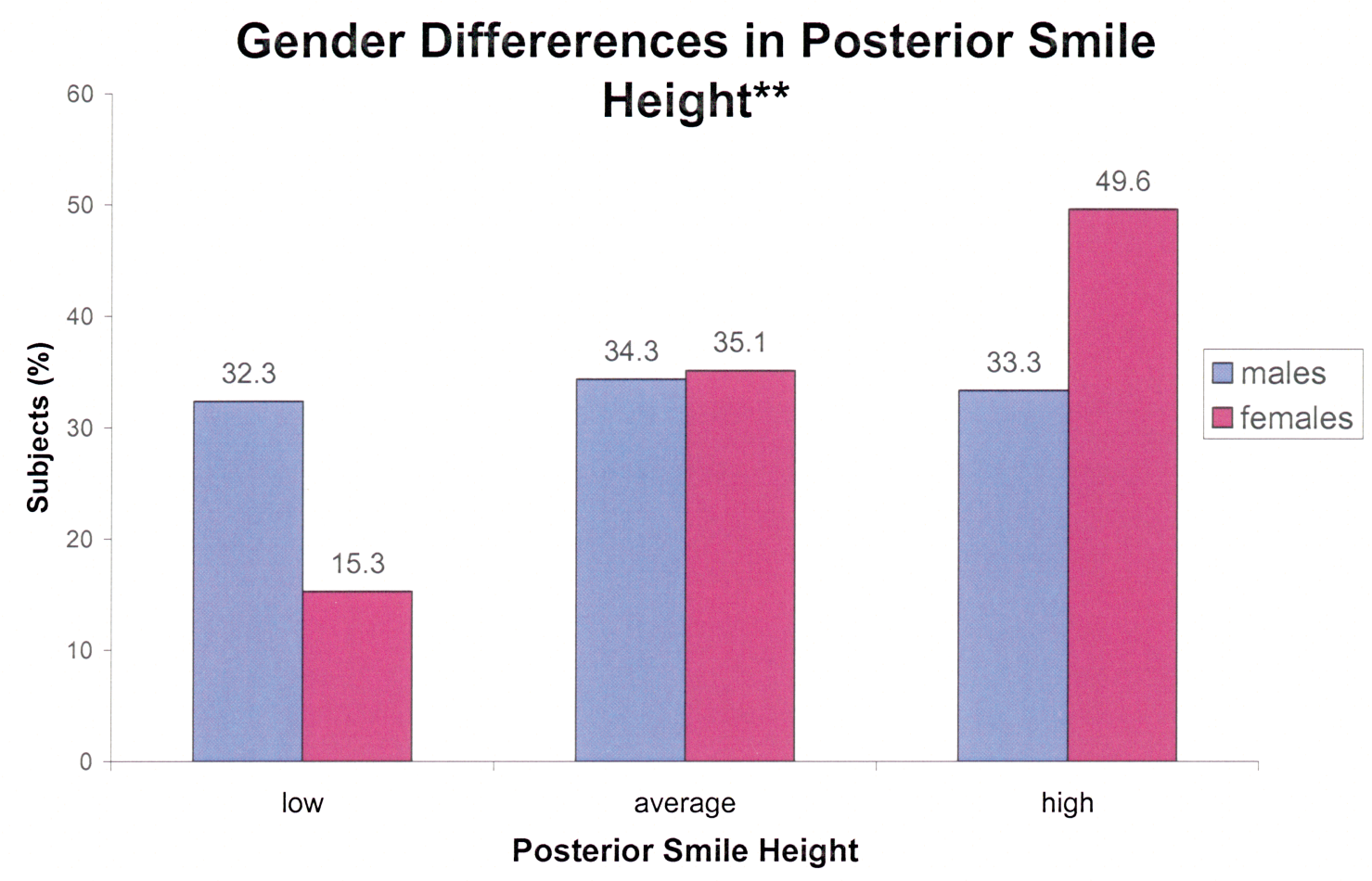

Figure 10. Comparison of the posterior smile height between males $(\mathrm{n}=99)$ and females $(\mathrm{n}=131){ }^{* *} \mathrm{p}>0.01$ 


\section{Gender Differerences in Smile Arc ${ }^{* * *}$}

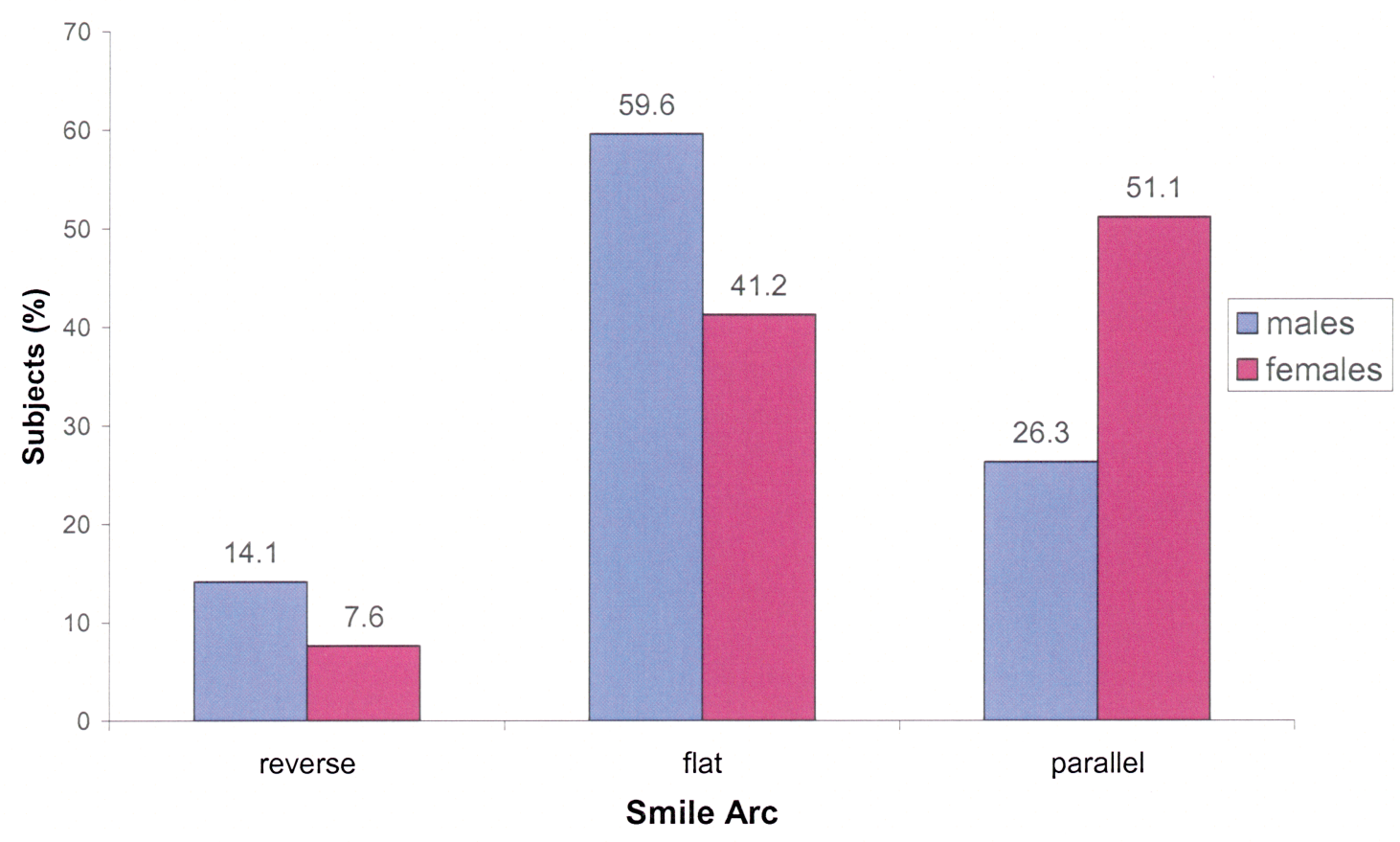

Figure 11. Comparison of the smile arc between males $(\mathrm{n}=99)$ and females $(\mathrm{n}=131)$. $* * * \mathrm{p}>0.001$ 


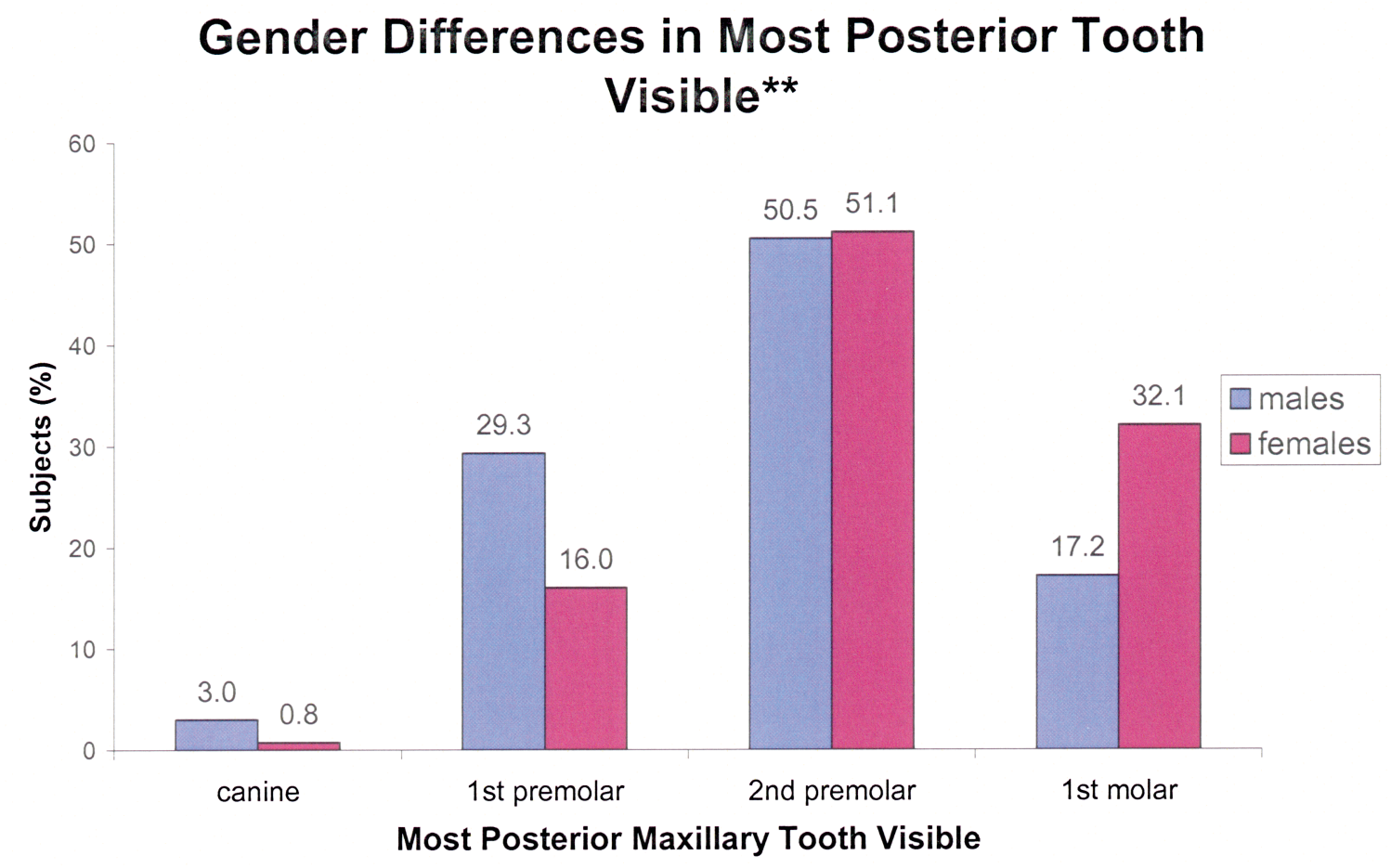

Figure 12. Comparison of the most posterior maxillary tooth visible between males $(\mathrm{n}=99)$ and females $(\mathrm{n}=131) . * * \mathrm{p}>0.01$ 


\section{Gender Differences in Buccal Corridor***}

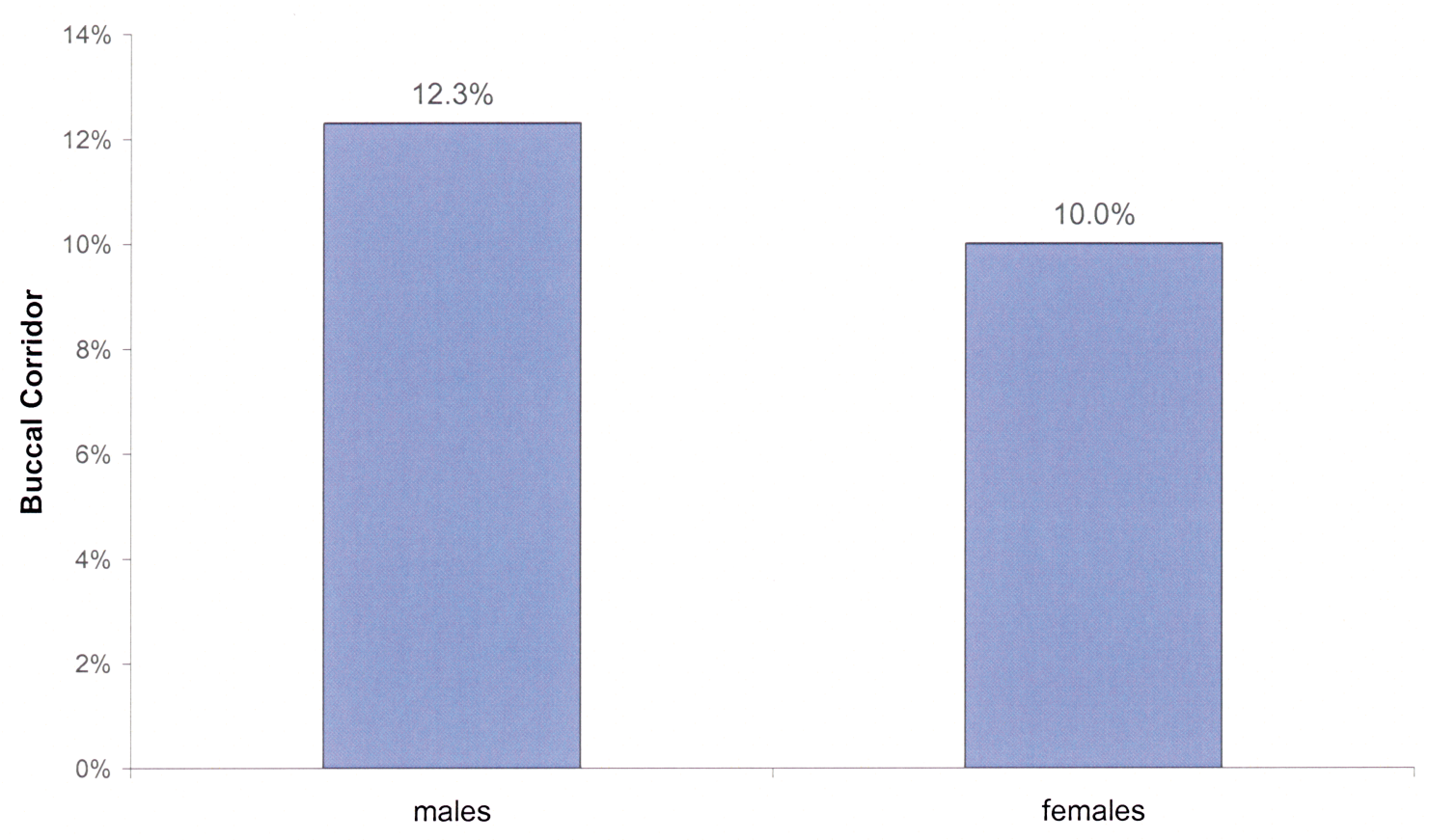

Figure 13. Comparison of the buccal corridor between males $(\mathrm{n}=99)$ and females $(\mathrm{n}=131) . * * * \mathrm{p}>0.001$ 


\section{Smile Arc Comparison**}

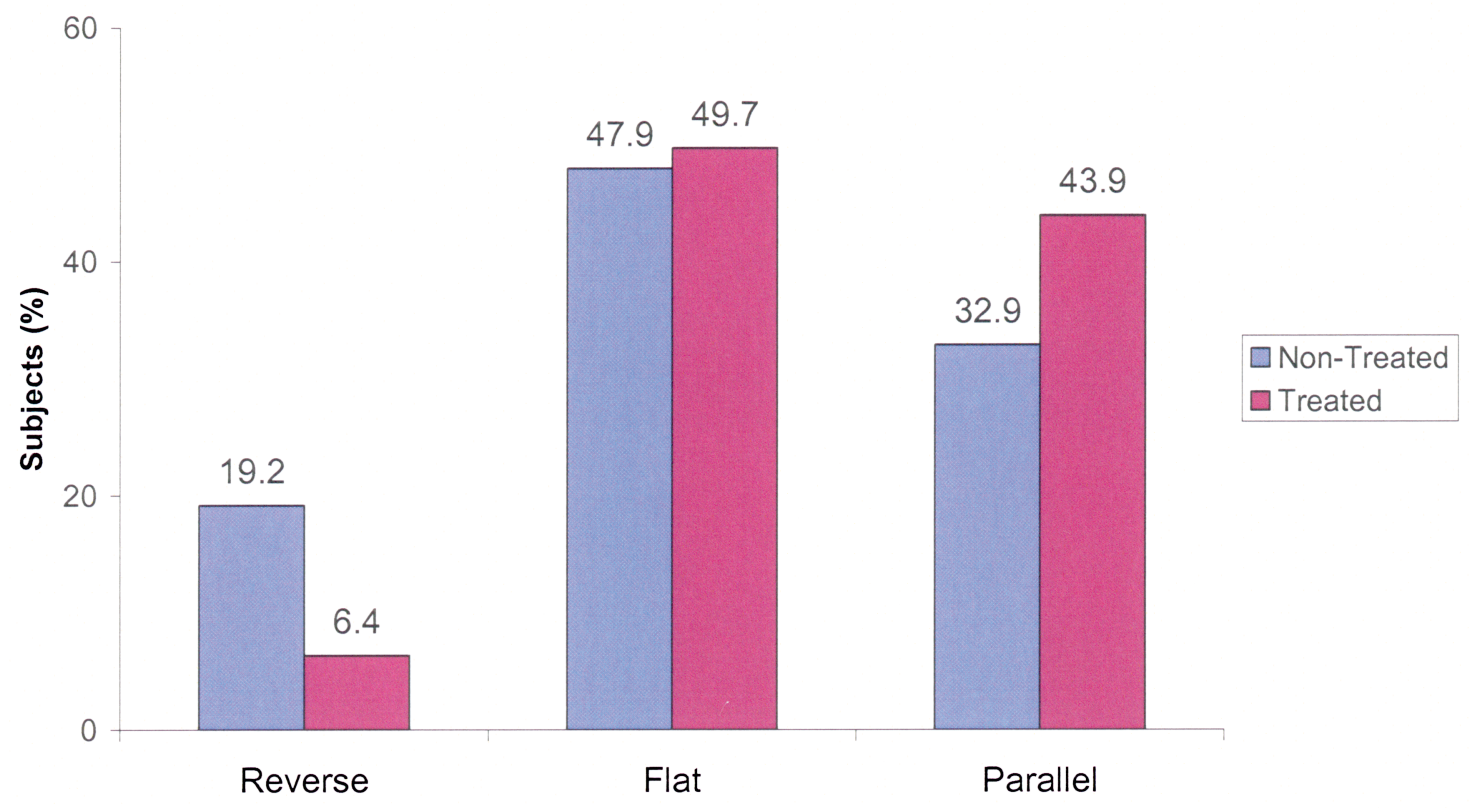

Figure 14. Comparison of the smile arc between the orthodontically treated $(\mathrm{n}=157)$ subjects and non-treated $(\mathrm{n}=73) .{ }^{* *} \mathrm{p}>0.01$ 


\section{Difference in Buccal Corridor*}

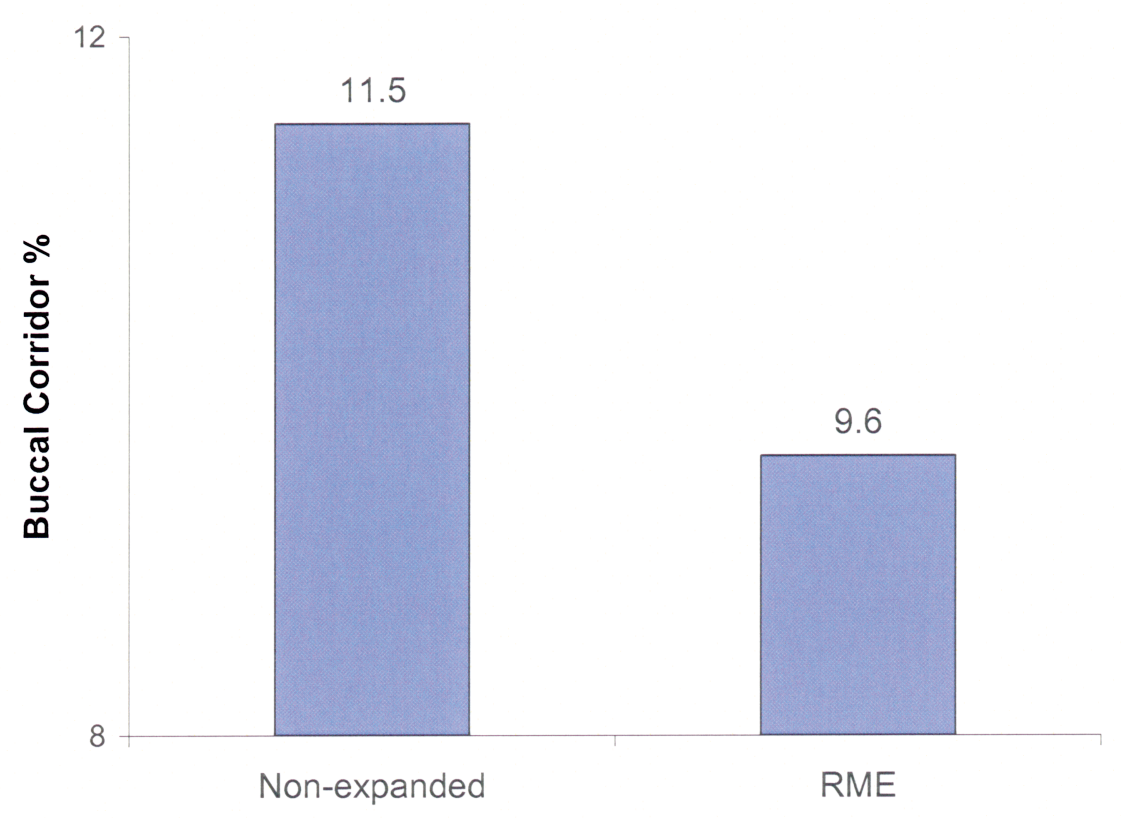

Figure 15. Comparison of Buccal Corridor between the rapid maxillary expanded $(n=70)$ subjects and non-expanded $(n=160) . * p>0.05$ 


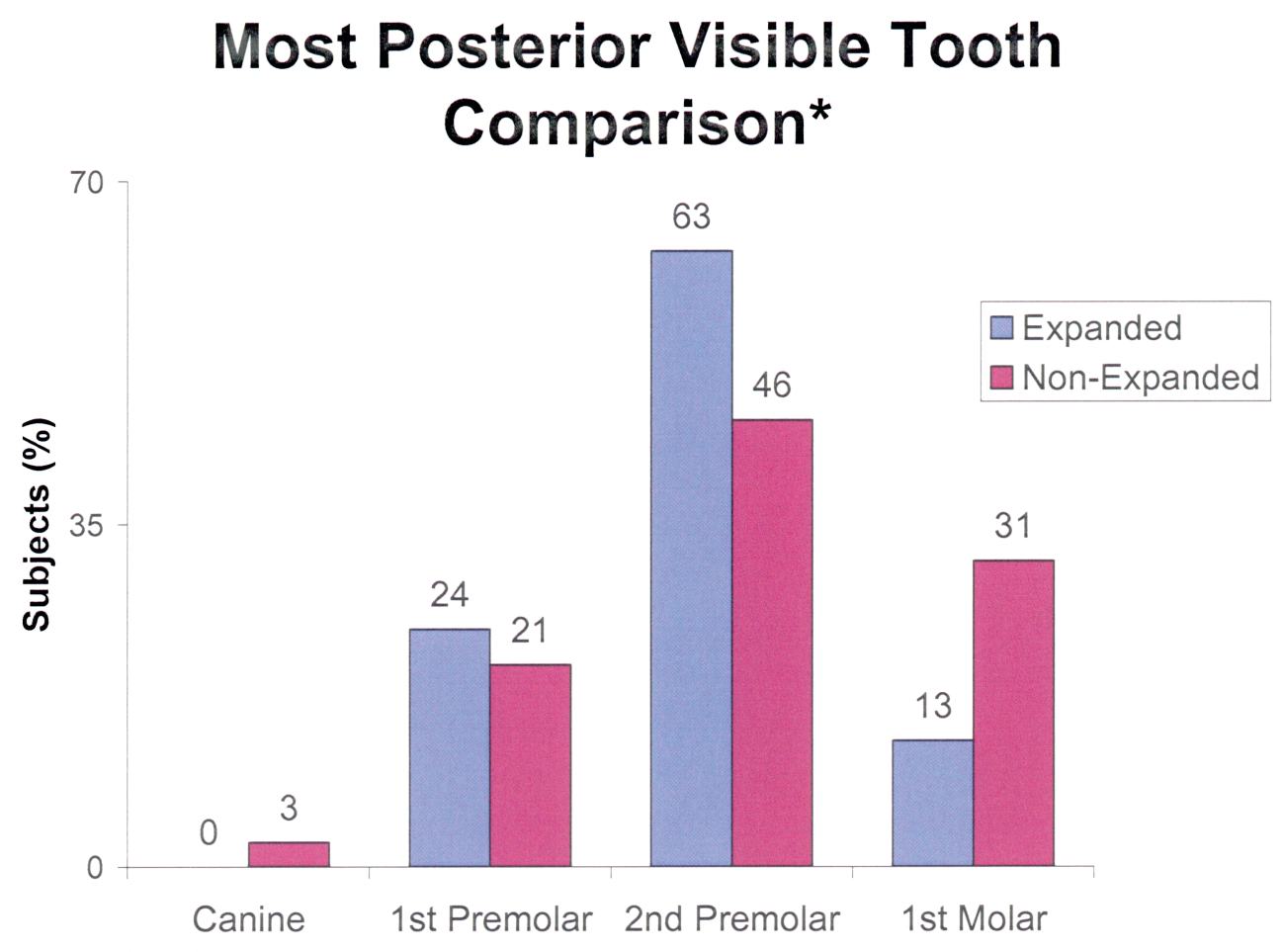

Figure 16. Comparison of most posterior maxillary tooth visible between the rapid maxillary expanded $(n=70)$ subjects and non-expanded $(n=160) . * p>0.05$ 


\section{Smile Arc vs. Anterior Smile Height}

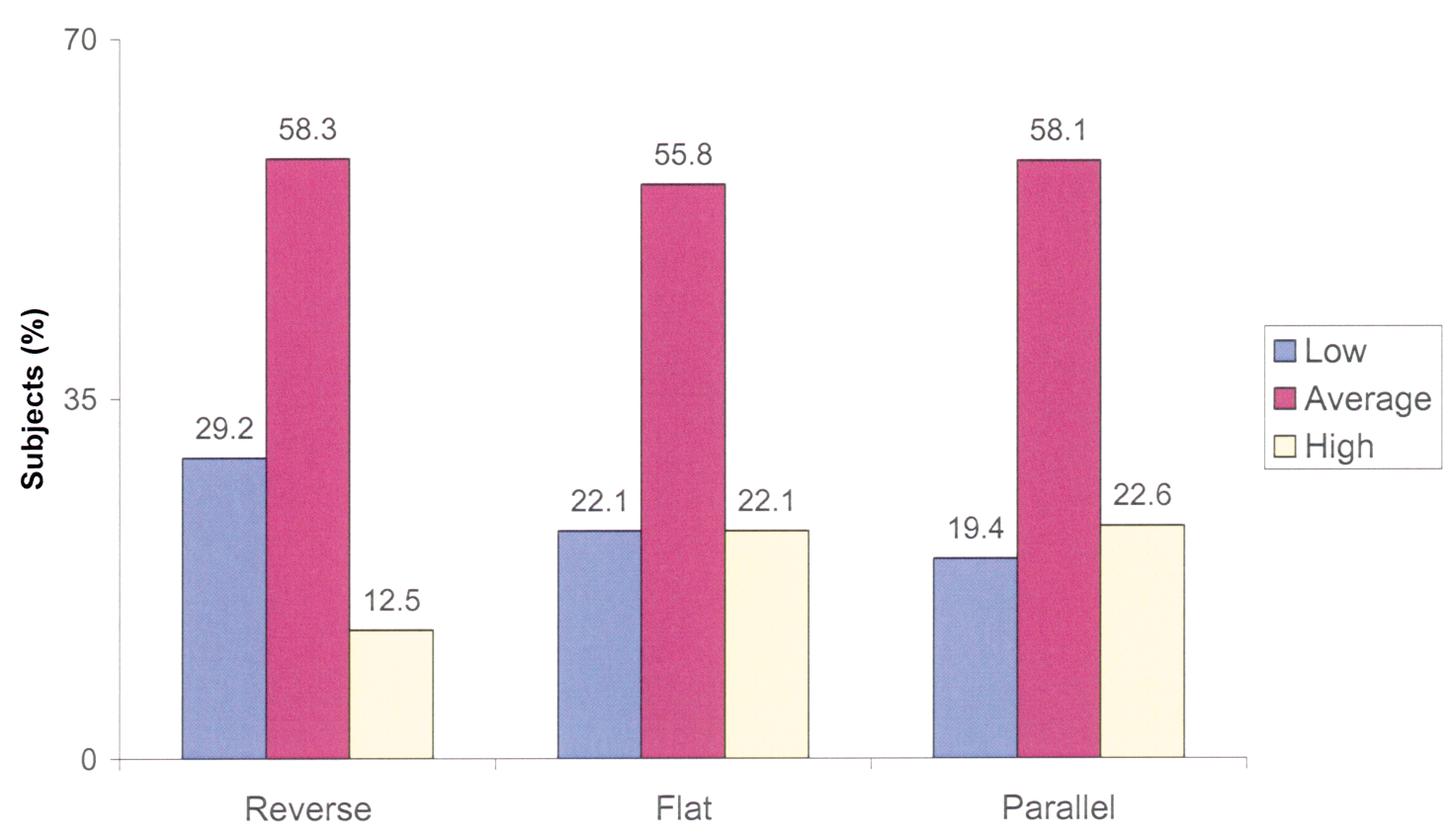

Figure 17. Relationship of smile arc to the anterior smile height for the total sample $(n=230)$. 


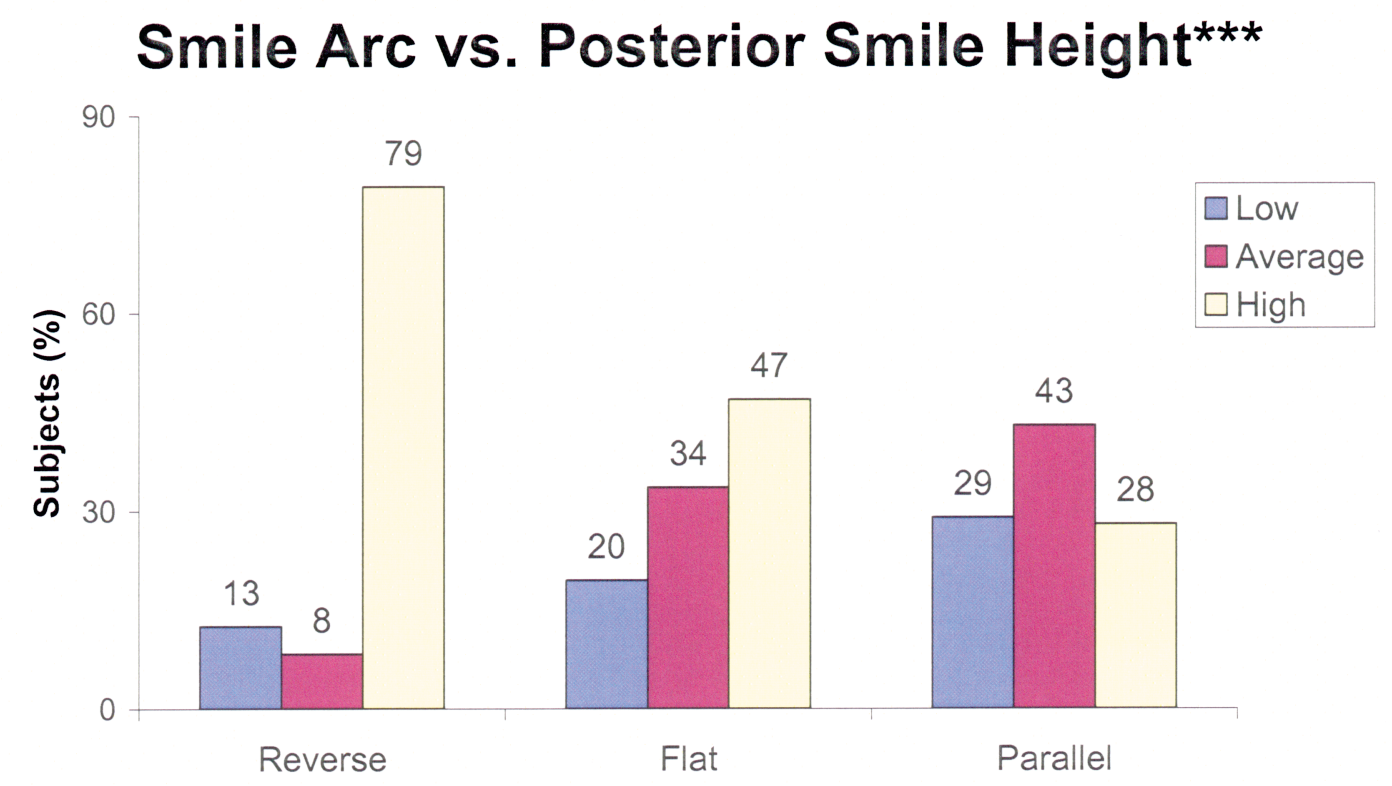

Figure 18. Relationship of smile arc to the posterior smile height for the total sample $(\mathrm{n}=230) . * * * \mathrm{p}>0.001$ 


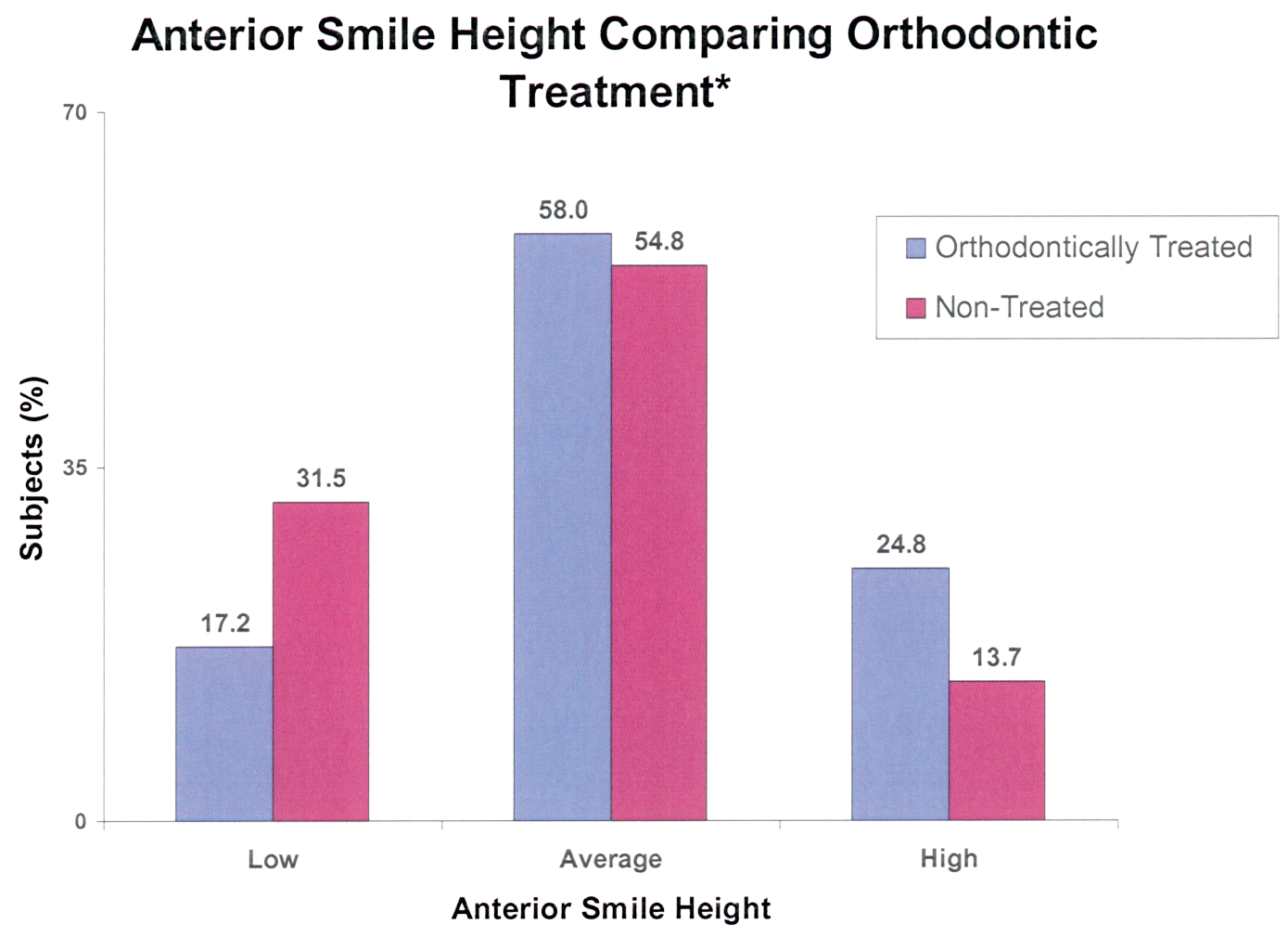

Figure 19. Difference in anterior smile height between orthodontically treated and non-treated. $* \mathrm{p}>0.05$ 


\section{Posterior Smile Height Comparing Orthodontic Treatment}

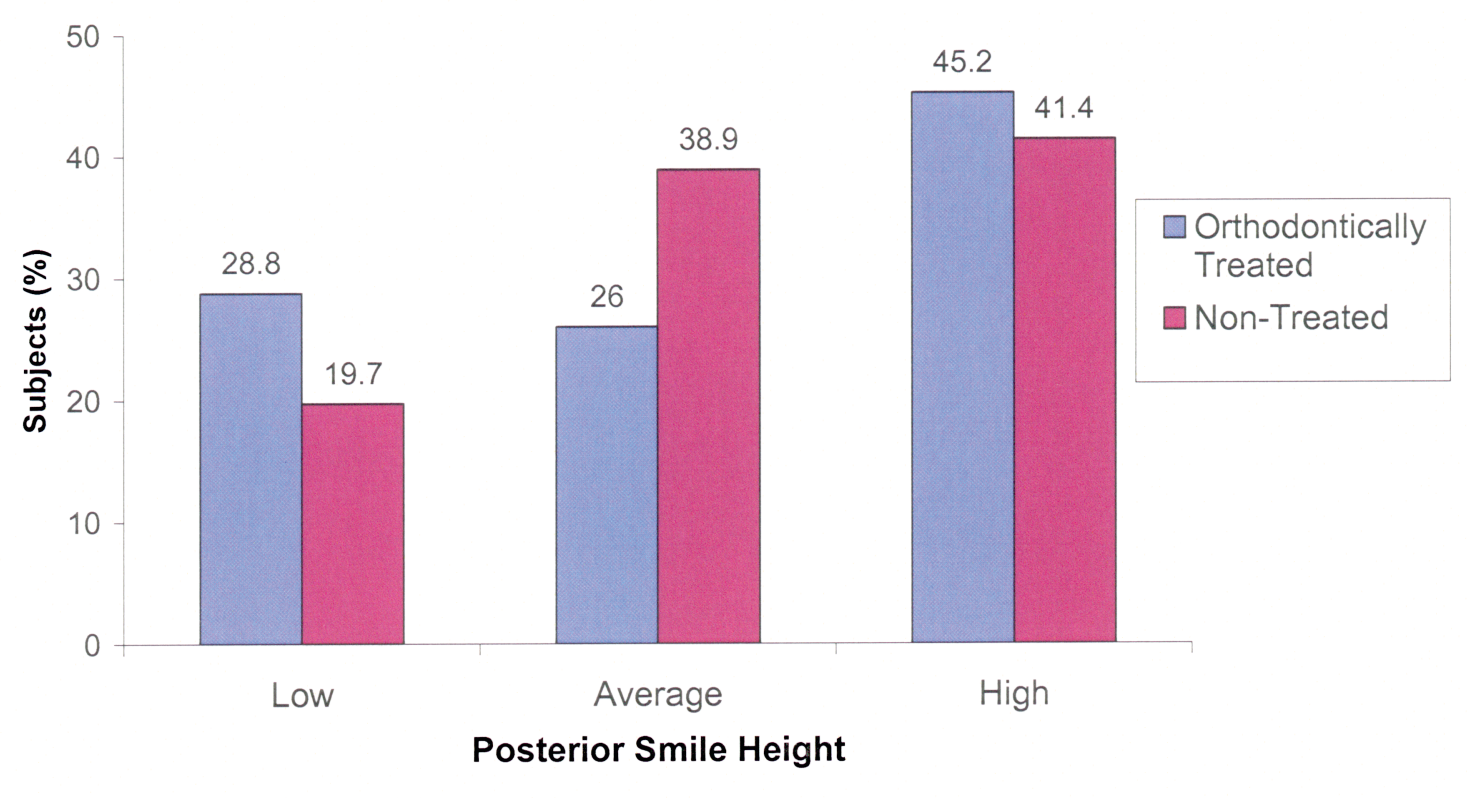

Figure 20. Difference in posterior smile height between orthodontically treated and non-treated. 


\section{Multiple Raters for the Smile Arc}

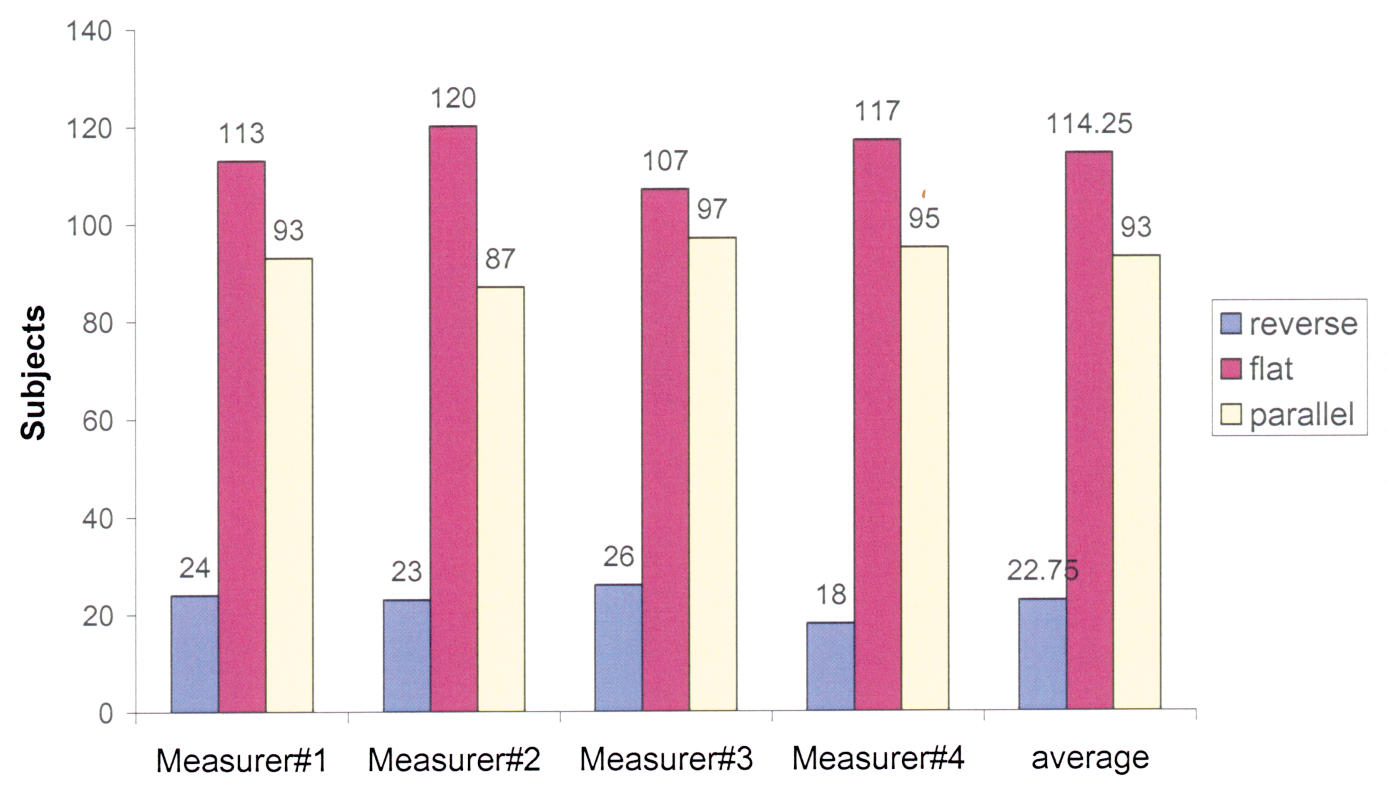

Figure 21. Multiple raters for the smile arc measurement. 


\section{$\underline{\text { Literature Cited }}$}


Ackerman, J. L., M. B. Ackerman, et al. (1998). "A morphometric analysis of the posed smile." Clin Orthod Res 1(1): 2-11.

Ackerman, M. B. and J. L. Ackerman (2002). "Smile analysis and design in the digital era." J Clin Orthod 36(4): 221-36.

Cohen, J. (1988). Statistical power analysis for the behavioral sciences. Hillsdale, N.J., L. Erlbaum Associates.

Dong, J. K., T. H. Jin, et al. (1999). "The esthetics of the smile: a review of some recent studies." Int J Prosthodont 12(1): 9-19.

Elston, R. C. and W. D. Johnson (1994). Essentials of biostatistics. Philadelphia, F.A. Davis Co.

Frush, J. P. (1966). "Linear occlusion." Ill Dent J 35(12): 788-94.

Hulsey, C. M. (1970). "An esthetic evaluation of lip-teeth relationships present in the smile." Am J Orthod 57(2): 132-44.

Isaacson, R. J. (1992). "Commentary: The gingival smile line." The Angle Orthodontist 62(No. 2): 101-102.

Johnson, D. K. and R. J. Smith (1995). "Smile esthetics after orthodontic treatment with and without extraction of four first premolars." Am J Orthod Dentofacial Orthop 108(2): 162-7.

McNamara, J. A. (2000). "Maxillary transverse deficiency." Am J Orthod Dentofacial Orthop 117(5): 567-70.

Moore, T., K. A. Southard, et al. (2005). "Buccal corridors and smile esthetics." Am J Orthod Dentofacial Orthop 127(2): 208-13; quiz 261.

Moorees CFA, K. M. (1958). "Natural head position: a basic consideration in the interpretation of cephalometric radiographs." Am J Phys Anthropol 16: 213234.

Peck, S. and L. Peck (1995). "Selected aspects of the art and science of facial esthetics." Semin Orthod 1(2): 105-26.

Peck, S., L. Peck, et al. (1992). "The gingival smile line." Angle Orthod 62(2): 91100; discussion 101-2.

Sarver, D. M. (2001). "The importance of incisor positioning in the esthetic smile: the smile arc." Am J Orthod Dentofacial Orthop 120(2): 98-111.

Sarver, D. M. and J. L. Ackerman (2000). "Orthodontics about face: the re-emergence of the esthetic paradigm." Am J Orthod Dentofacial Orthop 117(5): 575-6.

Sarver, D. M. and M. B. Ackerman (2003). "Dynamic smile visualization and quantification: part 1. Evolution of the concept and dynamic records for smile capture." Am J Orthod Dentofacial Orthop 124(1): 4-12.

Sarver, D. M. and M. B. Ackerman (2003). "Dynamic smile visualization and quantification: Part 2. Smile analysis and treatment strategies." $\underline{\text { Am J Orthod }}$ Dentofacial Orthop 124(2): 116-27.

Tjan, A. H., G. D. Miller, et al. (1984). "Some esthetic factors in a smile." J Prosthet Dent 51(1): 24-8. 
Appendix

\title{
A Dynamic Smile Analysis in Young Adults
}

\section{Questionnaire}

\author{
Christopher Maulik, DMD \\ Department of Orthodontics \\ University of Connecticut Health Center
}

Subject \#

Sex

male female

Age

Have you had orthodontic treatment?

yes or no

If yes to the above,

Have you had maxillary expansion? yes or no (RPE, rapid palatal expansion)

Have you had teeth extracted for orthodontic treatment?

yes or no 
